\title{
A Survey of Bariatric Surgical Patients' Experiences with Behavioral and Psychological Services
}

Jessica C. Peacock

West Virginia University

Follow this and additional works at: https://researchrepository.wvu.edu/etd

\section{Recommended Citation}

Peacock, Jessica C., "A Survey of Bariatric Surgical Patients' Experiences with Behavioral and Psychological Services" (2011). Graduate Theses, Dissertations, and Problem Reports. 3373. https://researchrepository.wvu.edu/etd/3373

This Dissertation is protected by copyright and/or related rights. It has been brought to you by the The Research Repository @ WVU with permission from the rights-holder(s). You are free to use this Dissertation in any way that is permitted by the copyright and related rights legislation that applies to your use. For other uses you must obtain permission from the rights-holder(s) directly, unless additional rights are indicated by a Creative Commons license in the record and/ or on the work itself. This Dissertation has been accepted for inclusion in WVU Graduate Theses, Dissertations, and Problem Reports collection by an authorized administrator of The Research Repository @ WVU.

For more information, please contact researchrepository@mail.wvu.edu. 

A Survey of Bariatric Surgical Patients' Experiences with Behavioral and Psychological
Services

Jessica C. Peacock, M.S.

Dissertation submitted to the Sport and Exercise Psychology Program, College of Physical Activity and Sport Sciences at West Virginia University in partial fulfillment of the requirements for the degree of

Doctor of Philosophy

In

Kinesiology with an emphasis in

Sport and Exercise Psychology

Samuel Zizzi, Ed.D., Chair

Edward Etzel, Ed.D.

Christiaan Abildso, Ph.D., MPH

Emily Murphy, Ph.D.

Melissa Olfert, Dr.PH., M.S., R.D.

Vanessa Shannon, Ph.D.

Morgantown, WV

2011

Keywords: behavioral modification, bariatric surgery, weight loss, physical activity 


\begin{abstract}
A Survey of Bariatric Surgical Patients' Experiences with Behavioral and Psychological Services
\end{abstract}

Jessica C. Peacock

The following study assessed behavioral and psychological services currently being used by bariatric patients before and after surgery. A convenience sample of $N=$ 380 was generated through solicitation on an online support website; inclusion criteria included having had surgery in the United States after implementation of accreditation standards in 2005. Participants completed an Internet-based survey that assessed services completed, satisfaction with services, perceived impact of surgery on mental and physical health as well as diet and physical activity behaviors, and current reported diet and physical activity behaviors. Overall, participants reported completing more services before surgery, and afterwards the most commonly reported completed services were support groups and dietary consultation; more than half of participants did not meet with either a mental health professional or exercise professional following surgery. Participants expressed high satisfaction with surgery, and perceived that surgery had a positive impact on health and health behaviors. Linear regression analysis showed that satisfaction with surgery was largely predicted by percent weight loss, though it is also possible that perceived benefits to mental and physical health also contributed to satisfaction levels. Self-reported physical activity levels were increased dramatically following surgery; however, these results must be interpreted carefully due to potential sample bias and over-reporting. Because participants in the current sample reported completing few behavioral and psychological services after surgery, it is recommended that bariatric facilities and insurance providers consider requiring patients to complete post-surgical behavioral modification programs that target improvement of diet and physical activity behaviors and overall lifestyle change. 


\section{Acknowledgements}

Thank you to my adviser and committee chair, Dr. Sam Zizzi, for giving me the freedom to complete the research that was meaningful to me, and for helping me to improve my abilities as a researcher and professional. Thank you also for the many wonderful opportunities that you have sent my way, especially my job. It has been such a rewarding experience, and allowed Justin and I both to finish school without any debt!

Thank you Dr. Ed Etzel, for the endless support and positive feedback. Your presence in my life and on my committee has not been taken for granted; you have taught me many valuable lessons that I will carry with me in all future endeavors.

Thank you Dr. Christiaan Abildso for never micromanaging, and for allowing me time to complete my research (and bother you for help) during work hours. Thank you also for actually reading my entire document and providing very useful feedback.

Thank you Drs. Emily Murphy, Melissa Olfert, and Vanessa Shannon for taking time out of your very busy schedules to serve on my committee, and for being excellent role models for a fellow woman in academia.

Thank you to Justine Vosloo and Alessandro Quartiroli for your friendship and support. You made graduate school and living in Morgantown not only bearable, but an experience to remember fondly.

Thank you to my parents and sisters, without whom I would never have gotten this far. Most importantly, thank you Justin. Words just wouldn't do it justice. 


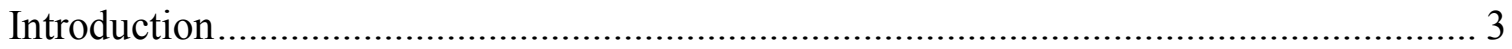

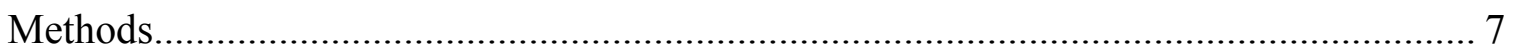

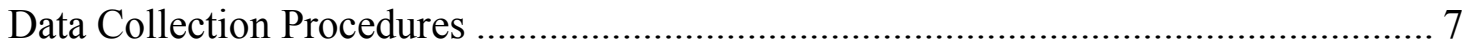

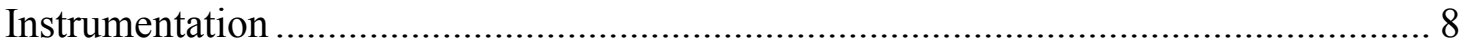

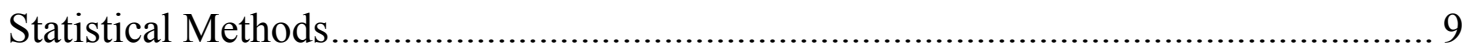

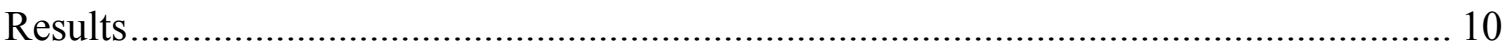

Services Completed Before and After Surgery ..................................................... 11

Satisfaction with Surgery and Associated Services .............................................. 12

Impact of Surgery on Perceived Health and Behavioral Habits ............................... 12

Relationship between Health Behaviors and Weight Loss ..................................... 14

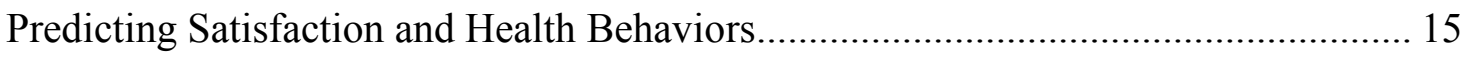

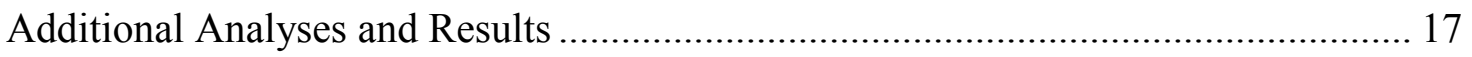

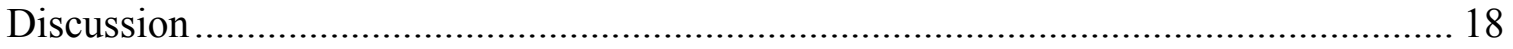

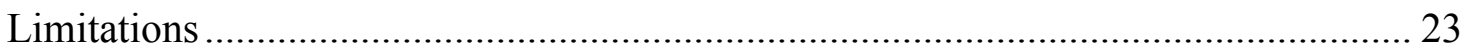

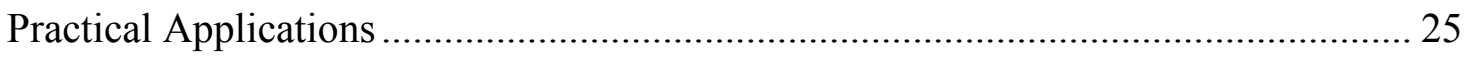

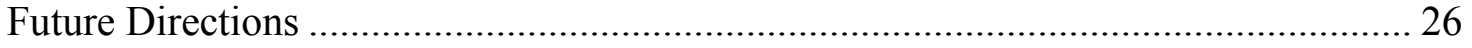

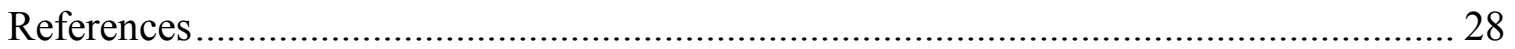

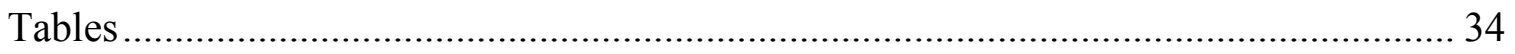

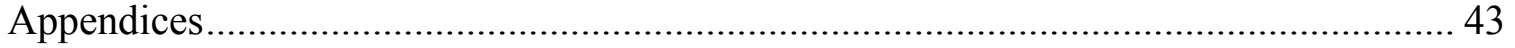

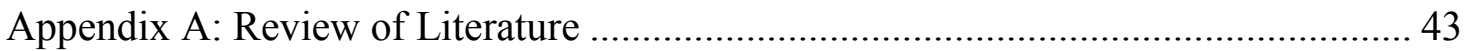

The Use and Efficacy of Behavioral Modification in the Treatment of Obesity ........ 44

The Use and Efficacy of Bariatric Surgery in the Treatment of Obesity ................... 57

The Use and Efficacy of Behavioral Modification and Bariatric Surgery in

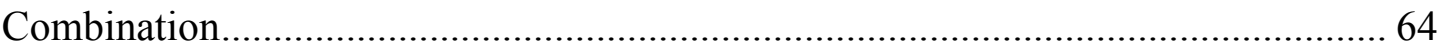

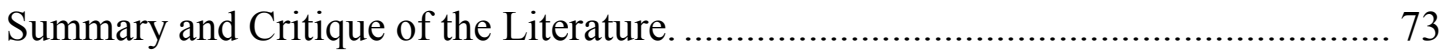

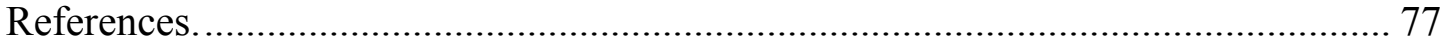

Table 1: Comparison of Weight Loss Outcomes among Behavioral and Surgical

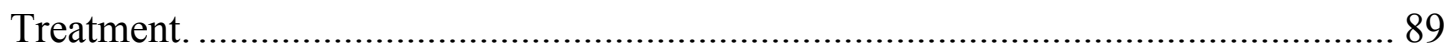

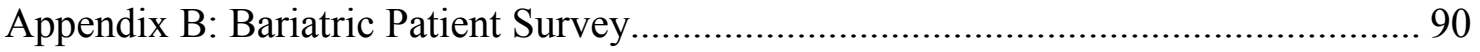


List of Tables

Table 1: Participant demographics... 34

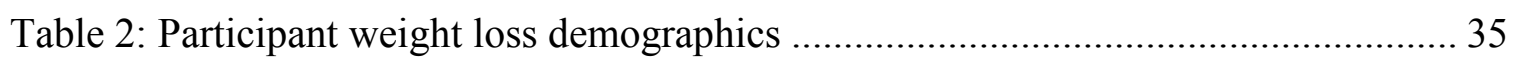

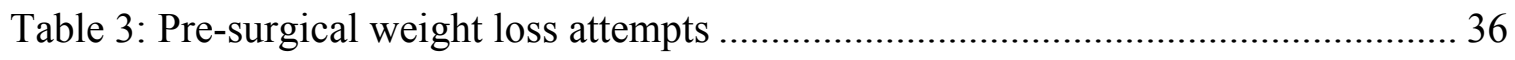

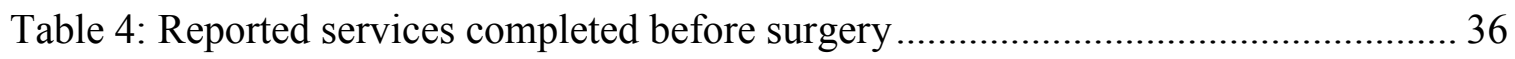

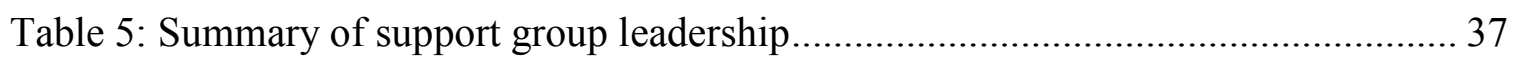

Table 6: Reported services (psychological and behavioral) completed after surgery ...... 37

Table 7: Frequency of meetings with bariatric professionals ..................................... 38

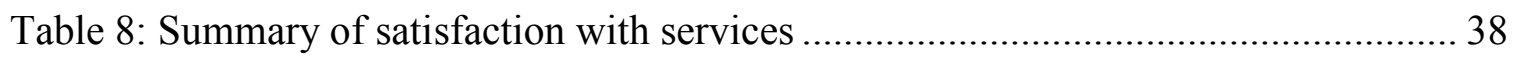

Table 9: Summary of perceived impact of surgery ratings .......................................... 39

Table 10: Summary of participant physical activity behaviors ..................................... 40

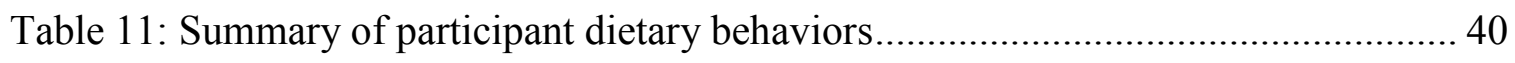

Table 12: Summary of exposure to behavioral modification principles.......................... 41

Table 13: Summary of response to use of potential service ....................................... 42 


\section{Introduction}

Obesity, defined as having a body mass index (BMI) of $\geq 30 \mathrm{~kg} / \mathrm{m}^{2}$, replaced smoking as the leading cause of morbidity and mortality in 2010 (Toussi, Fujioka, \& Coleman, 2009). It is estimated that obesity costs Americans upwards of 90 billion dollars in direct health care costs every year (Joyal, 2004; Karmali \& Shaffer, 2005), largely due to increased use of prescription medications and higher rates of hospitalization associated with co-morbidities such as type-II diabetes and cardiovascular disease (Bachman, 2007). Indirect costs can be just as severe, including increased use of sick leave and an estimated 52.5 million days of lost productivity that cost employers approximately four billion dollars annually (Cerulli \& Malone, 1998). These costs will continue to have a profound economic impact as long as the prevalence of obesity remains high; currently, about $30 \%$ of the adult population is obese, and $5 \%$ can be categorized as extremely or morbidly obese (Flegal, Carroll, Ogden, \& Johnson, 2002; Wadden \& Tsai, 2006).

For the large number of adults who are obese, personal consequences may be debilitating as well. Obese individuals are more likely to report perceived discrimination, and greater difficulty finding educational and vocational opportunities (Herpertz, Kielmann, Wolf, Langkafel, Senf, \& Hebebrand, 2003). In addition, negative health may increase physical limitations, contributing to lower perceived health-related quality of life as well as overall quality of life (Cerulli \& Malone, 1998; Karlsson, Taft, Rydén, Sjöström, \& Sullivan, 2007). With such a large potential market, it is not surprising that medical and commercial sectors have a high interest in selling weight loss through a variety of methods (Hamilton \& Greenway, 2004).

While there are many contributing factors to the development of obesity, including genetic, environmental, and social factors, it is commonly accepted that an imbalance between 
energy intake and energy expenditure often underlies excessive weight gain (Cerulli \& Malone, 1998; Lemmens, Oenema, Klepp, Henrickson, \& Brug, 2008). In fact, the increasing prevalence of overweight and obese individuals between the 1970's and 2000's was paralleled by an increase in reported average energy intake and a decrease in reported leisure-time physical activity (Joyal, 2004). Because of this clear link between energy balance and weight status, the cornerstone of treatment for obesity has traditionally been behavioral modification, otherwise known as behavioral treatment or lifestyle modification (Sarwer, von Sydow Green, Vetter, \& Wadden, 2009). Behavioral modification is typically comprised of changes to diet and physical activity patterns, as well as behavior therapy to provide techniques for maintaining these changes and avoiding maladaptive habits (Sarwer et al., 2009).

Unfortunately, the long-term effectiveness of behavioral modification for weight loss is not high, as more than $50 \%$ of patients treated with behavioral modification return to baseline weight within five years of treatment (Perri \& Corsica, 2002). Therefore, alternative treatments for managing the obesity epidemic have become increasingly popular, including pharmacological and surgical methods (Joyal, 2004). Bariatric surgical procedures for the treatment of obesity were developed in the 1950's, and are primarily reserved for cases of morbid obesity $\left(\mathrm{BMI} \geq 40 \mathrm{~kg} / \mathrm{m}^{2}\right.$ or BMI $>35 \mathrm{~kg} / \mathrm{m}^{2}$ with comorbid conditions such as type-II diabetes and hypertension) (Karmali \& Shaffer, 2005); however, the United States Food and Drug Administration recently approved the use of surgical LAP-Band procedures for individuals with a BMI $\geq 30$ (U.S. Food and Drug Administration, 2011). The American Dietetics Association published a position paper in favor of bariatric surgery as the "most effective" approach for weight management for obese individuals (Rowe \& Davis, 2007), and currently about 220,000 bariatric surgeries are performed each year (American Society for Metabolic and 
Bariatric Surgery, 2011). However, while outcome data support that surgical treatment produces increased weight loss and improvements in associated co-morbidities (Maggard et al., 2005), long-term studies examining weight loss after bariatric surgery have found that $20-30 \%$ of patients fail to reach typical postoperative weight loss (Sarwer et al., 2009), and 10-25\% fail to maintain weight loss after 10 years (Collazo-Clavell, Clark, McAlpine, \& Jensen, 2006). These numbers may not even be an accurate representation of patients who struggle to lose or maintain weight losses, as it is well documented that many patients fail to attend long-term follow-up appointments (Gould, Beverstein, Reinbardt, \& Garren, 2007; Wolfe, Kortner, \& Kuhlmann, 2001) and may not be included in survey data.

One explanation for why some individuals experience difficulty losing weight or maintaining weight loss after bariatric surgery is non-adherence to dietary and physical activity recommendations (Collazo-Clavell et al., 2006). Examination of weight control behaviors among individuals who have successfully maintained long-term weight loss determined that physical activity levels were lower and fat intake higher for those who lost weight through surgical means in comparison to those who utilized other methods (Klem et al., 2000). In addition, several studies of outcome following gastric banding or gastric bypass surgery have found increased physical activity adherence to be a strong predictor of weight loss and weight loss maintenance (Colles, Dixon, \& O’Brien,2008; Welch et al., 2008). These trends implicate the importance that behavioral lifestyle factors, including regular exercise and proper diet, may play in long-term success at weight loss. Thus, while the American Dietetics Association has endorsed bariatric surgery for the treatment of obesity, it also suggested that comprehensive pre- and post-surgical behavioral therapy be implemented in order to maximize long-term outcomes (Rowe \& Davis, 2007). 
However, while psychologists and psychiatrists are often utilized to provide assessment of individuals seeking bariatric surgery (Wadden \& Sarwer, 2006), structured programs providing ongoing behavioral management after surgery do not appear to be common (Peacock $\&$ Zizzi, 2011). Thus, it is not surprising that postsurgical bariatric patients are often noncompliant with the lifestyle modifications necessary to maintain weight loss, such as consuming a low-fat diet and meeting recommended guidelines for physical activity (Behrns, Smith, Kelly, \& Sarr, 1993; Elkins et al., 2005). Many in the bariatric field recognize the need for long-term commitment to behavioral and lifestyle change (Brandenburg \& Kotlowski, 2005; Joyal, 2004); however at present no standards exist for how to best help bariatric patients to make and adhere to these changes. While it has been recommended that mental health services be provided to bariatric patients for longer than six months post-surgery (Greenberg, Sogg, \& Perna, 2009), what is not presently clear is what psychological and behavioral services are currently being provided to patients undergoing bariatric surgery, how often they are received, and the qualifications of those providing these therapies. While accreditation procedures exist for bariatric surgical facilities (American College of Surgeons, 2010; Pratt, McLees, \& Pories, 2006), there is no standard of care regarding behavioral modification; therefore, the current role and effectiveness of behavioral modification programs in bariatric surgery outcomes cannot fully be appreciated.

Thus, a review of behavioral services offered to bariatric patients is warranted. A better understanding of patient perceptions of and satisfaction with current services will help to determine whether the needs of individuals undergoing weight loss surgery (WLS) are being met, and if not, what services may need to be added or enhanced to maximize outcomes. In 
addition, it is worthwhile to explore if patients who received a higher quantity or quality of behavioral support experienced greater satisfaction and/or weight loss.

The primary purpose of the following research was to examine the pre- and post-surgical behavioral and psychological services completed by post-surgical bariatric patients via internet survey. A secondary purpose was to determine relationships between services completed and patient outcomes; thus, this research study also assessed patient satisfaction with services, perception of the impact of surgery on health and health behaviors, and self-report outcomes such as weight, food consumption, and physical activity patterns.

\section{Methods}

\section{Data Collection Procedures}

The sample for this study $(N=380)$ was solicited for participation from an online support website called ObesityHelp.com. ObesityHelp.com was established as a peer-support community in 1998, and has a membership of more than 600,000. Following approval of the study and survey, an administrator for the website placed a link and information about the survey in the site's January 2011 email newsletter, which maintains a membership of about 160,000. Starting one week after the distribution of the newsletter, the first author also posted daily links and information about the survey in several discussion boards on ObesityHelp.com for a duration of three weeks. Discussion boards ranged from having 310 members to 5,569 members who had posted to the forum within the last year.

At the end of data collection a total of 590 respondents had begun the survey; of these, 465 survey responses were complete (78.5\%). Upon analysis of the complete data, 66 surveys were removed because the respondent's date of surgery fell outside of the inclusion criteria (between January 1, 2006 and July 1, 2010) and 19 were removed because the respondent 
reported having surgery in a country outside of the United States. These inclusion criteria were utilized to ensure the sample had undergone surgery after accreditation standards had been implemented in the U.S. in 2005. A final sample size of $N=380$ was thus used for all data analyses.

\section{Instrumentation}

The survey for this study (see Appendix B) was hosted online at Survey Monkey.com, and was based on the results of previous research into services at accredited bariatric facilities. Peacock and Zizzi (2011) utilized document analysis of websites of facilities accredited by the American College of Surgeon's Bariatric Surgical Center Network to summarize common services offered to surgical patients both before and after surgery, and the results of this study were used as a basis for the creation of the survey. Sections of the survey included: pre-surgical information, general surgical information, psychological services, dietary services, exercise services, lifestyle services, current diet and physical activity habits, and demographic information.

In addition to items regarding description of general medical, psychological, and behavioral services, the survey also assessed for participants' satisfaction with said services and their perception of the impact of having surgery on their physical health, mental health, eating habits, and physical activity levels. To assess these items, a 5-point Likert scale was used, ranging from "very positive impact" to "no impact." The perceived impact of surgery on mental and physical health was weighted on a scale ranging from -2 to +2 , while scales measuring the perceived impact of surgery on dietary and physical activity habits ranged from 1 to 5 . The survey also solicited information about participants' actual physical activity habits before and after surgery, as well as for their reported current fruit and vegetable intake. To assess these 
health habits, modified items from the Behavioral Risk Factor Surveillance System (BRFSS; Centers for Disease Control, 2002) were used. Other patient outcomes that were assessed included weight loss, occurrence of medical complications, and treatment for common comorbidities such as high blood pressure and type-II diabetes.

While survey items based on existing measures with established validity and reliability were used where possible, the majority of the survey was created for the purposes of the current study. Construction of the survey and specific items was thus completed utilizing principles of tailored design outlined by Dillman (2000) in order to enhance readability, comprehension, and response rate. For instance, less potentially sensitive information was solicited earlier in the survey, while information regarding psychological and behavioral experiences was included later. Also, the same question structure was used for items asking for similar information, and additional instructions prefaced any set of questions addressing the same construct (i.e., the impact of surgery on mental health, diet, or exercise behaviors).

\section{Statistical Methods}

SPSS v.19 was used for all statistical analyses. Descriptive statistics, including frequencies, means, and standard deviations, were used to assess for demographic information, completed psychological and behavioral services, satisfaction ratings, perceptions of the impact of surgery on health and health behaviors, and dietary and physical activity patterns. Pearson correlation coefficients were used to determine relationships between weight loss outcomes and dietary and physical activity patterns, and linear regression analyses were utilized to explore factors that predict patient outcomes.

Five separate linear regression models were completed using stepwise methods in order to determine variables that may predict satisfaction with surgery and weight loss, physical 
activity, and dietary outcomes. Stepwise methods were chosen for all models in order to complete exploratory model building, as there is currently a lack of existing research on the relationship between services utilized by bariatric patients and outcomes (Field, 2010). Prior to regression analysis, correlations were completed for all potential independent variables. Due to low variability in response and lack of significant correlation with dependent variables, the demographic variables of gender, income, and educational level were excluded from regression testing. The independent variable of satisfaction with exercise services was removed from all regression testing as well, as only 163 participants provided response for this variable and the smaller sample size would have compromised power. Statistical significance was set at $p<.05$ for all analyses.

\section{Results}

The current sample of $N=380$ included 360 female (94.7\%) and $20(5.3 \%)$ male participants. The mean age of participants was 47 years $(\mathrm{SD}=9.21)$, average weight before surgery was $129.51 \mathrm{~kg}(\mathrm{SD}=23.80)$, and on average participants were 22 months removed from surgery $(\mathrm{SD}=13.75)$. The average percent of original body weight lost was $36.1 \%(\mathrm{SD}=11.08)$. See Tables 1-2 for comprehensive participant demographics. Prior to having surgery, participants reported attempting to lose weight via a number of different methods; $80.8 \%$ reported using Weight Watchers, 75.3\% reported using exercise, and 72.6\% reported taking medication. In addition, $40.0 \%$ of participants reported trying some combination of multiple methods to lose weight before having surgery. See Table 3 for a full description of pre-surgical weight loss attempts. The large majority of participants $(85.3 \%)$ reported that having bariatric surgery was a "personal choice," while the remaining $13.9 \%$ indicated that surgery was completed following 
physician recommendation. Among the most common surgical methods reported, Roux-en-Y gastric bypass $(58.7 \%)$ was indicated most frequently followed by gastric banding $(22.4 \%)$.

\section{Services Completed Before and After Surgery}

Prior to surgery, the majority of participants reported attending an informational seminar $(90.3 \%)$ as well as consults with a medical (99.2\%), psychological (91.8\%), and dietary professional (92.4\%); however, consultation pre-surgery with an exercise professional (30.5\%) was less common. About $65 \%$ of participants reported attending at least one support group before surgery, while $55.5 \%$ reported attending an educational class; only $31.6 \%$ reported attending multiple classes related to making lifestyle change prior to having surgery. See Table 4 for a summary of pre-surgical completed services.

After surgery, the most commonly reported psychological or behavioral service completed was attendance at group counseling or a support group (53.4\%). The majority of participants $(41.1 \%)$ reported that "psychologist" was the title of the professional who provided counseling services; however, support group leadership varied immensely. See Table 5 for a summary of reported support group leaders. While completion of dietary services post-surgery was less common than reported pre-surgery, use of dietary consultation, counseling, or classes was still reported more frequently than use of post-surgical exercise-related services such as consultation or counseling. See Table 6 for a summary of post-surgical completed services. The frequency of reported meetings with professionals also varied significantly, with the majority of participants reporting one to three visits with a surgeon, nurse or physician assistant, and dietitian in the first year after surgery, and zero visits with a mental health or exercise professional postsurgery. See Table 7 for a summary of the frequency of meetings. 


\section{Satisfaction with Surgery and Associated Services}

Average overall current satisfaction with surgery using a 5-point Likert scale was high $(\mathrm{M}=4.54 ; \mathrm{SD}=.95)$; this was very similar to mean reported satisfaction at three months postsurgery $(M=4.46 ; S D=1.02)$. However, satisfaction with specific types of services was lower, with average satisfaction for psychological $(\mathrm{M}=3.39 ; \mathrm{SD}=1.46)$ and dietary $(\mathrm{M}=3.38 ; \mathrm{SD}=$ 1.41) services and satisfaction with support group experience $(\mathrm{M}=3.54 ; \mathrm{SD}=1.33)$ rated higher than average satisfaction for exercise services $(\mathrm{M}=2.89 ; \mathrm{SD}=1.49)$. A repeated measures ANOVA was computed comparing mean satisfaction among the psychological and behavioral services, and satisfaction for exercise services was significantly lower than satisfaction scores for the other services, $F(2.70,163)=21.72, p<.001, \eta^{2}=.219$. A total aggregate satisfaction score for psychological and behavioral services was calculated by summing individual satisfaction scores for the various services; with a highest possible score of 20 (indicating very high satisfaction), the average rating was $13.77(\mathrm{SD}=4.39)$. Overall, participants reported very high satisfaction with their surgical experience, and somewhat positive ratings for the supplemental services they received. For a summary of mean satisfaction scores, see Table 8 .

\section{Impact of Surgery on Perceived Health and Behavioral Habits}

Prior to surgery, the most commonly reported rating for participant mental health was "somewhat good" (37.3\%); the most common reported perceived impact of surgery on mental health was then found to be "very positive impact" at both 3 months post-surgery (48.5\%) and currently (68.9\%). Prior to surgery physical health was most commonly reported as "not at all good" (39.3\%), while most participants reported the perceived impact of surgery on physical health to be "very positive impact" at 3 months post-surgery (55.0\%) and currently (85.1\%).

While the perceived impact of surgery on mental and physical health continued to improve over time, the perceived impact of surgery on participant eating habits actually 
decreased from 3 months post-surgery to currently. The most frequent reported rating of eating habits was "not at all good" (36.9\%) before surgery; at 3 months post-surgery $70.3 \%$ of participants rated the impact of surgery as "very positive" but this decreased to $55.6 \%$ currently. The impact of surgery on physical activity levels was assessed only for 3 months post-surgery, as pre-surgical and current behaviors were solicited and will be discussed subsequently. Following surgery, $43.5 \%$ of participants reported "somewhat higher" levels of physical activity. For a summary description of the perceived impact of surgery on health and health behaviors, see Tables 9.

Participant physical activity patterns were solicited both pre- and post-surgery. On average, participants reported completing approximately 29.02 minutes $(\mathrm{SD}=24.79)$ of moderate physical activity an average of 1.63 days per week $(\mathrm{SD}=1.73)$, and 21.79 minutes $(\mathrm{SD}$ $=32.75)$ of vigorous physical activity an average of .54 days per week $(\mathrm{SD}=1.04)$ before surgery. The total number of average reported minutes of moderate physical activity per week before surgery was $60.93(\mathrm{SD}=119.91)$ and total average minutes of vigorous physical activity per week before surgery was $21.70(\mathrm{SD}=54.34)$. After surgery, participants reported an average of 42.63 minutes $(\mathrm{SD}=33.10)$ of moderate physical activity on an average of 3.82 days per week $(\mathrm{SD}=2.00)$ and 41.73 minutes $(\mathrm{SD}=33.36)$ of vigorous physical activity an average of 2.19 days per week $(\mathrm{SD}=2.04)$. Total average minutes per week of moderate physical activity after surgery was $188.89(\mathrm{SD}=212.12)$, and average total minutes of vigorous physical activity per week after surgery was $110.43(\mathrm{SD}=151.09)$. Guidelines for weekly physical activity indicate that adults should complete 150 minutes or more of moderate physical activity, 75 minutes or more of vigorous physical activity, or an equivalent combination of moderate and physical activity each week (American Heart Association, 2011). Based on these recommendations, approximately 65 
participants (17\%) were meeting guidelines before surgery and $236(62 \%)$ reported current activity levels sufficient for meeting physical activity guidelines.

Recommendations for fruit and vegetable intake indicate that adults should consume between four and six servings of fruits and vegetables (Center for Disease Control and Prevention, 2011); because the sample for this study was comprised primarily of women, the recommended guideline of two fruit servings and three vegetable servings was used to determine how many participants were meeting guidelines. The average daily reported servings of fruit was $1.49(\mathrm{SD}=1.05)$ and the average daily servings of vegetables was $2.15(\mathrm{SD}=1.20)$. Based on reported daily servings, it was determined that $20.5 \%$ of participants are currently meeting recommended guidelines of 2 or more servings of fruits and 3 or more servings of vegetables. Approximately $70.7 \%$ of participants reported some daily fruit and vegetable intake, while $3.2 \%$ reported no daily servings. See Tables 10-11 for a summary of participant physical activity and dietary behaviors.

\section{Relationship between Health Behaviors and Weight Loss}

Reported weekly minutes of both moderate and vigorous physical activity were positively and significantly related to percent of weight loss, $r(357)=.17, p<.001$ (moderate physical activity), $r(361)=.20, p<.001$ (vigorous physical activity); however, the effect size was small. For correlation coefficients, weak effects are indicated by correlations $<.30$, moderate relationships by correlations between .30 and .60 , and strong relationships by correlations $>.60$. Combined total daily servings of fruits and vegetables was not significantly correlated with participant percent of weight loss, $r(374)=.06, p=.27$. 


\section{Predicting Satisfaction and Health Behaviors}

For linear model one, the dependent variable was current overall satisfaction with surgery, and the independent variables included weight at time of surgery, percent weight loss, initial satisfaction with surgery, total number of psychological and behavioral services completed (out of a total of 15), satisfaction with psychological services, satisfaction with support group experience, and satisfaction with dietary services. Multicollinearity tests showed no problems with the remaining independent variables.

Analyses showed that neither total number of services completed nor satisfaction with support group experience were predictive of overall current satisfaction with surgery. In addition, the significant contribution of satisfaction with dietary services was small and only accounted for $1 \%$ of variance; thus this variable was not included in the final regression model. The final model chosen explained $41 \%$ of the variance in overall current satisfaction with surgery, $R^{2}=.41$, $F(4,304),=52.78, p<.001$. The largest individual contributor to variance in satisfaction ratings was percent weight loss, $R^{2}$, percent explained $=.195, \beta=.38, p<.001$, followed by initial satisfaction with surgery, $R^{2}$, percent explained $=.13, \beta=.31, p<.001$, satisfaction with psychological services, $R^{2}$, percent explained $=.06, \beta=.25, p<.001$, and weight at time of surgery, $R^{2}$, percent explained $=.03, \beta=.16, p<.001$. This model suggests that satisfaction scores can be predicted by those with higher percent weight loss, higher satisfaction ratings with initial surgery and psychological services, and those participants who started at higher weights.

The remaining regression analyses examined the predictive value of the independent variables of total number of psychological and behavioral services completed, satisfaction with psychological services, satisfaction with support group experience, satisfaction with dietary services, weight at time of surgery, and amount of time since surgery for the dependent variables 
of percent weight loss, current reported minutes of weekly moderate physical activity, current reported minutes of weekly vigorous physical activity, and total combined servings of fruits and vegetables. Multicollinearity tests for all analyses showed no issues with highly correlated predictor variables. For the regression model examining variance in percent weight loss, only two variables contributed significantly: satisfaction with dietary services $\left(R^{2}\right.$, percent explained $=$ $.04, \beta=.20, p<.001)$ and weight at time of surgery $\left(R^{2}\right.$, percent explained $\left.=.02, \beta=.12, p<.001\right)$. The model accounted for a total of $5.5 \%$ of the variance in percent weight loss overall, $R^{2}=.055$, $F(2,306)=8.99, p=.03$. This model suggests that a small amount of percent weight loss can be predicted by starting weight and satisfaction with dietary services, with participants who were heavier at the time of surgery and who expressed higher satisfaction with dietary services losing a larger percent of their initial body weight.

For the regression models examining variance in moderate and vigorous physical activity, only one variable, total psychological and behavioral services completed, was found to contribute significant variance, though this contribution was small: $R^{2}=.03, F(1,291)=8.06, \beta$ $=.16, p=.005$ for moderate physical activity, and $R^{2}=.05, F(1,296)=16.41, \beta=.23, p<.001$ for vigorous physical activity. Finally, the only significant contributor to the regression model for fruit and vegetable intake was satisfaction with psychological services, $R^{2}=.017, F(1,303)=$ $5.17, \beta=.13, p=.02$. Thus, while effects are small (for $R^{2}$, small effects are those between .01 .08 ; moderate effects are those between .09-.24; and large effects are those $>.25$ ) participants who completed more psychological and behavioral services were more likely to accumulate more minutes of moderate and physical activity each week, and participants who are more satisfied with psychological services are more likely to eat a higher number of fruits and vegetables each week. 


\section{Additional Analyses and Results}

In addition to providing descriptive information about the types of psychological and behavioral services offered at bariatric facilities, participants were also asked about education and information they were exposed to regarding common principles of behavior modification for weight loss such as self-monitoring goal-setting, identifying barriers, and finding support. Overall, the majority of participants reported exposure to behavioral modification related to dietary and overall lifestyle change; however, reported exposure to principles of behavior change related to exercise were not as commonly reported. See Table 12 for a summary of exposure to behavioral modification principles.

Participants were also asked whether they would have participated in additional psychological and lifestyle change services had they been offered at the bariatric facility. About $44.1 \%$ of participants indicated that they would use regular counseling services if included at no additional cost; another $15.0 \%$ said they would be willing to pay out-of-pocket costs and $19 \%$ reported they would not utilize regular counseling even if available. When asked if they would attend a program targeting lifestyle change, $49.9 \%$ replied that they would if the service was included at no additional cost, while $13.2 \%$ reported willingness to pay out-of-pocket. In addition, another $20.8 \%$ of participants indicated that a program focused on lifestyle change was available at their bariatric facility and that they used the service. For a summary of responses see Table 13.

Finally, participants were asked about physical activity habits specifically related to strength training. About $54.9 \%(n=207)$ of participants reported not currently completing strength training on a regular basis, while $45.1 \%(n=170)$ reported completing at least some strength training on a regular basis. Of those who reported they did complete strength training, 
$47.4 \%(n=81)$ reported doing so three times per week, and another $31.6 \%(n=54)$ reported completing strength training twice per week.

\section{Discussion}

Upon examination of the services reported by the sample in this study, it appears that bariatric patients are currently receiving more support and education from multidisciplinary professionals before surgery than after. This pattern of services is not surprising, as accreditation standards emphasize the need for psychological evaluation and dietary assistance prior to approval for surgery, and many insurance providers require such consultations (Toussi et al., 2009). However, it is concerning that following surgery so few study participants reported completion of support services related to managing psychological factors or diet and exercise behaviors. In fact, the majority of participants ( $57 \%$ and $53 \%$ respectively) reported no contact with a psychological or exercise professional in the twelve months following surgery. Of particular note is the lack of reported services completed relating to exercise, as regular physical activity is a strong predictor of long-term weight loss maintenance (Colles, Dixon, \& O’Brien, 2008; Welch et al., 2008). Therefore, it would seem that services geared towards helping bariatric patients adopt and maintain regular exercise patterns might be helpful for maintenance of weight loss after surgery. Of all the services assessed, exercise services also received the lowest satisfaction rating, which might indicate that participants would like to see more or improved services to help them manage their physical activity behaviors.

Despite expressing less frequent completion of and lower satisfaction with exerciserelated services, the participants in this study did report a large increase in regular physical activity from pre- to post-surgery. Based on self-report, prior to surgery only $17 \%$ of participants were meeting guidelines for physical activity, while currently $62 \%$ meet recommendations. 
However, there are several reasons why these results should be considered carefully. First, the current sample must be compared to the overall bariatric surgical population. The majority of participants were white females, who are typically overrepresented in the bariatric population (Flum, Khan, \& Dellinger, 2007), and reported a much higher level of education and income than what is typically found among obese populations (Worthy, Lokken, Pilcher, \& Boeka, 2010), but is common among bariatric patients (Flum et al.). Existing literature notes a clear correlation between education and income level and physical activity habits (McNeill, Kreuter, \& Subramanian, 2006), so this sample, and the bariatric population as a whole, may be more likely to meet physical activity guidelines because they are more highly educated and have greater access to resources outside of the bariatric facility that have helped them change their exercise levels. In particular, this sample was generated from a support-based website that provides information and resources, some of which are related to changing physical activity behaviors. The sample in this study may have been more likely to seek out education and support than patients from the general bariatric population, which could also have led to increased physical activity levels when compared to patients who do not use the support website. In addition, use of the Internet may also reflect on the lack of services reported completed after surgery, as participants could have neglected in-person follow-up in favor of web-based support.

Another reason to consider reported changes in physical activity carefully is the potential bias in self-report data. Obese individuals have been found to commonly over-report or overestimate exercise, and may not have accurate perceptions of what qualifies as moderate or vigorous exercise (Brown \& Werner, 2008; Jakicic, Polley, \& Wing, 1998). In addition, the retrospective nature of self-report and demand characteristics may lead some participants to identify higher levels of physical activity than are actually completed. The results of several 
studies lend credence to the possibility that physical activity levels among the current study are over-reported. Tucker, Welk, and Beyler (2011) found that while $62 \%$ of adults self-reported meeting physical activity guidelines, objective accelerometer data showed that only $9.6 \%$ of adults were completing activities sufficient to be counted as moderate or vigorous physical activity. While this sample was generated via large-scale survey of all Americans, Bond et al. (2010) examined pre- to six months post-surgery physical activity levels among a sample of twenty surgical patients using both self-report and accelerometer data. Prior to surgery the authors found that self-report and accelerometer data were identical among the $10 \%$ of participants who reported meeting physical activity guidelines. However, after surgery 55\% of participants reported meeting guidelines while accelerometer data indicated that only $5 \%$ were completing levels of physical activity that met these guidelines. While Bond et al.'s sample was small, the authors postulated that this discrepancy in reported physical activity could have been due to enhanced perceptions of physical function, which the current sample clearly indicated was improved following surgery.

Overall, participants reported being very satisfied with their surgery and the services they received. Regression analyses showed that of the variables examined, greater percent weight loss was the best predictor of satisfaction with surgery; however, this satisfaction may also be related to the improvements participants reported experiencing in both their mental and physical health. As an example, treatment for comorbidities such as high blood pressure decreased from about $64 \%$ of the sample being treated before surgery to $18 \%$ being treated currently, and treatment for depression or anxiety decreased by $21 \%$ following surgery. In addition, reported physical activity levels increased dramatically after surgery, and this increase in exercise may impact participants' mood, which could in turn affect perceptions of health and satisfaction with surgery. 
The reported impact of surgery on participants' dietary habits was also high, though it is interesting that this impact decreased for some participants as time since surgery increased (i.e. at three months post-surgery $70 \%$ rated the impact as "very high" but for current impact this rating dropped to $56 \%$ ). Since participants were close to two years post-surgery on average, this decrease in impact may indicate that over time participants begin to struggle more with maintaining changes to their eating habits. Additional chi-square analyses were completed comparing time since surgery in six month intervals and whether participants were meeting guidelines for fruit and vegetable intake; while results were not significant, $\chi^{2}=7.32, p=.29$, fewer participants were meeting guidelines when three years or more post-surgery. Currently only around $21 \%$ of the total sample reported meeting guidelines for fruit and vegetable intake, and intake was not correlated with weight loss outcome. Thus, it may be that participants still require assistance and support for adopting and sticking with healthy eating changes, or could benefit from increased intensity or frequency of services during the first year after surgery. Many bariatric patients may feel their dietary habits have improved because surgery inherently helps limit portion sizes; however, patients may need increased education regarding the importance of a balanced diet for proper nutrition and prevention of vitamin deficiencies, as well as assistance identifying fruits and vegetables that are well-tolerated following surgery.

Currently, accreditation standards via the ASMBS Center of Excellence and the ACS Bariatric Surgical Center Network require that surgical facilities have follow-up protocols in place to assist patients in rehabilitation and long-term follow-up, including procedures for psychological, dietary, and exercise counseling (American College of Surgeons, 2010; Mechanick et al., 2008). However, these standards are vague, and thus implementation may vary significantly. For example, while more than half of the current sample reported attendance at a 
support group or group counseling following surgery, making it the most utilized post-surgical service, it is unclear how support groups are used and what content is included due to the lack of specific guidelines for implementation. In addition, as leadership for support groups appears highly varied, it may be possible that some content areas, such as physical activity behaviors or emotion management, may not always be addressed.

Comprehensive behavior modification programs that teach participants the skills needed to change and maintain lifestyle behaviors such as diet and physical activity patterns might be useful additions to post-surgical care. These programs could be provided using qualified professionals from many disciplines (i.e., psychology, dietary, and exercise professionals) and teach principles such as self-monitoring, stimulus control, and cognitive restructuring. Among the current sample, fewer than half of participants reported exposure to principles of behavior modification, especially related to changing exercise habits. However, a large number of participants did report exposure to these principles related to making dietary changes. This discrepancy in services may be because dietary services are required more frequently than postsurgical psychological services or exercise services. Therefore, to potentially improve long-term weight loss maintenance, it might be beneficial for facilities or third party providers to require participation in post-surgical programs or services. Currently, most insurance providers require patients to complete a medically supervised weight loss program and a psychological evaluation prior to surgery (Frezza, 2006); however, requirements following surgery do not seem to be common. Because compliance with follow-up services may decrease once approval for surgery has been obtained, requiring patients to complete services could potentially enhance long-term outcomes if patients learn skills and receive support to make lasting changes to their lifestyle habits. For instance, insurance providers could require patients to complete medical weight 
management following surgery rather than before; this would provide patients greater support for making and maintaining changes after surgery and incentivize completion of services.

\section{Limitations}

The use of self-report measures was a primary limitation of this study. Self-report requires that individuals be honest and accurate in their response in order for results to be valid. Many participants may have inflated self-reported outcomes such as weight loss and physical activity levels in order to appear successful, and there is some existing research that supports that bariatric patients over-report physical activity habits (Bond et al. 2010). However, ensuring anonymity of results and prompting participants to be truthful in their responses may have decreased the effects of social desirability. Self-report measures were also solicited from patients who are multiple years out from their surgical experience, and thus some patients may have had difficulty accurately recalling the services offered during weight loss surgery.

The survey utilized in this study was piloted with a small number of individuals in order to ensure that items were understandable and that survey length promoted completion. However, the survey may lack internal reliability and validity, as most items were created for the study and were not fully piloted with an appropriate population. Where possible, items from existing instruments [e.g., the Behavioral Risk Factor Surveillance System (BRFSS); Centers for Disease Control, 2002] were utilized; however, BRFSS items were designed for assessment by phone, and thus modification of items for print may have decreased some reliability and validity. Some items within the survey may not have adequately assessed the services bariatric patients complete after surgery. Support groups seem to be utilized by most participants, but content is likely highly varied. Therefore, some participants may have indicated completing services such 
as counseling or classes related to making dietary or exercise changes, when really these were topics covered within the support group setting.

Another limitation was the use of a convenience sample. In order to generate a sample size that allowed for adequate power in statistical analyses, recruiting participants from the ObesityHelp.com website was warranted; however, generating an accurate response rate using the described methodology was not possible and external validity is limited as generalizations cannot be made fully to the greater population. This sample was demographically representative of the bariatric population as a whole; however, it may also be a unique subset of this population as participants were clearly invested in seeking out support as many as five years after surgery and this characteristic could be related to outcomes. A randomized sample of patients would have been preferable; however, the convenience sample was necessary in order for the study to remain feasible and allowed for a large sample of participants from multiple surgical facilities across the Unites States to report on current services.

Finally, extraneous variables such as social support, resources, and socioeconomic status may impact weight loss and other outcomes (i.e. increased physical activity, increased fruit and vegetable consumption, etc.), and could therefore have biased patient responses. For example, research clearly illuminates a relationship between increased physical activity and decreased levels of depression and negative mood (PAGAC, 2008). If patients incorporated increased physical activity into their daily lives despite a lack of exercise-related bariatric services, they may still have reflected positively on their weight loss surgical experience because of increased perceptions of positive well-being. Conversely, patients who were highly satisfied with their surgery may have been more likely to rate all aspects of their surgical experience and behavioral outcomes positively due to this satisfaction. 


\section{Practical Applications}

The results of this research indicate a link between behavioral and psychological services completed post-surgery and increased weekly minutes of physical activity; in addition, minutes of physical activity were positively correlated with weight loss. Since most bariatric patients do not meet recommended guidelines for physical activity prior to surgery, and many may not fully understand what qualifies as moderate or vigorous physical activity, the addition of services related to helping bariatric patients increase exercise patterns could enhance long-term outcomes. Initially patients may need assistance learning what qualifies as physical activity and what activities can be completed taking possible physical limitations or comorbidities into account. However, once patients progress with weight loss and improve in physical functioning and mobility, follow-up services can address more detailed exercise prescriptions including progressive cardiovascular and strength training as well as long-term action plans for maintaining exercise habits. Currently, it is likely that discussion of physical activity recommendations is being completed by other professionals (i.e. physicians, nurse practitioners, or dietitians); however to provide patients in-depth information and education about how to incorporate physical activity into their new lifestyle, exercise science professionals should be included in aftercare services. Bariatric facilities should have at least one exercise professional on staff to work with patients throughout their first year post-surgery, or partner with a fitness facility that can accommodate patients in adopting and maintaining a physical activity program.

In addition, facilities should provide patients with ongoing psychological and mental health support, particularly in the first year following surgery. A psychologist, licensed professional counselor, or other mental health professional with bariatric experience should also be on staff, and be available to patients for regular counseling or consultation. Because the most 
frequently used post-surgical service is currently attendance at a support group, mental health professionals should also supervise and facilitate these groups, as they are most qualified to manage potentially sensitive topics, such as changes to personal relationships and identity, and teach principles of cognitive behavioral modification for weight management.

\section{Future Directions}

Current accreditation standards recommend the use of a multidisciplinary team before and after surgery; however, this research indicates that some professionals, especially mental health and exercise professionals, are not commonly interacting with patients after surgery has been completed. Bariatric surgical facilities and insurance providers should consider implementing post-surgical requirements in order to increase the likelihood that patients receive exposure to support, skills, and education from individuals with expertise in changing lifestyle habits. In addition to access to dietary professionals to help manage good nutrition and postsurgical mental health services to assess how patients are adjusting to a new way of life after surgery, insurance providers could also cover gym membership or personal training for patients to help them adopt or resume exercise after surgery. The sample in this study reported a high level of physical activity following surgery, but previous literature indicates that more research is needed to determine if bariatric patients are actually exercising at levels sufficient enough to meet recommended guidelines; in the meantime third-party sponsored services could help patients learn how to be active in order to maximize long-term surgical results.

While it is clear that participants in this study are satisfied with their surgical experience and perceive vast improvements in mental and physical health, many may still not be adequately modifying lifestyle habits that could assist them in maintaining weight loss long-term. Thus, while bariatric surgery is largely heralded as the most effective treatment for long-term weight 
loss among morbidly obese individuals, suboptimal weight loss continues to be an issue for many bariatric patients (Sarwer et al., 2009), and providing increased support and education to patients to help them change behavior could lead to enhanced outcomes. Previous reviews of bariatric surgical facility websites have shown that rhetoric describing surgery as a "tool" that cannot be used successfully without lifestyle change is common. In addition, while obesity is largely ascribed to factors outside the patient's control (i.e. genetics, the environment), failure to lose weight or sustain losses after surgery is more frequently attributed to individual behavior and non-adhere to this new lifestyle (Salant \& Santry, 2005). Unfortunately, while facilities expect patients to be able to make significant changes to diet and exercise habits, the data indicate that services are rarely provided or utilized in order to help them get there. 


\section{References}

American College of Surgeons. (ACS; 11 January 2008). ACS Bariatric Surgery Center Network Accreditation Program (ACS BSCN). Bariatric accreditation program manual. Retrieved from http://www.acsbscn.org/docs/Program\%20Manual\%20V2.11-1-08.pdf.

American Heart Association. (AHA; 19 January 2011). American Heart Association guidelines. Retrieved from http://www.heart.org/HEARTORG/GettingHealthy/PhysicalActivity/ American-Heart-Association-Guidelines_UCM_307976_Article.jsp.

American Society for Metabolic and Bariatric Surgery. (ASMBS; January 2011). Fact sheet: Metabolic and bariatric surgery. Retrieved from http://www.asmbs.org/Newsite07/ media/ASMBS_Metabolic_Bariatric_Surgery_Overview_FINAL_09.pdf. Accessed January 3, 2011.

Behrns, K. E., Smith, C. D., Kelly, K. A., \& Sarr, M. G. (1993). Reoperative bariatric surgery: Lessons learned to improve patient selection and results. Annals of Surgery, 218, 646653.

Bond, D. S., Jakicic, J. M., Unick, J. L., Vithiananthan, S., Pohl, D., Roye, G. D., et al. (2010). Pre- to postoperative physical activity changes in bariatric surgery patients: Self-report vs. objective measures. Obesity, 18, 2395-2397.

Brandenburg, D. \& Kotlowski, R. (2005). Practice makes perfect? Patient response to a prebariatric surgery behavior modification program. Obesity Surgery, 15, 125-132.

Brown, B. B. \& Werner, C. M. (2008). Using accelerometer feedback to identify walking destinations, activity overestimates, and stealth exercise in obese and nonobese individuals. Journal of Physical Activity and Health, 5, 882-893. 
Centers for Disease Control and Prevention. (CDC; December 2002). 2003 Behavioral risk factor surveillance system state questionnaire. Retrieved from http://www.cdc.gov/brfss/questionnaires/pdf-ques/2003brfss.pdf.

CDC. (2010). Know the amounts you need each day. Retrieved from http://www.fruitsandveggiesmorematters.org/?page_id=62.

Cerulli, J. \& Malone, M. (1998). Outcomes of pharmacological and surgical treatment for obesity. Pharmacoeconomics, 14, 269-283.

Collazo-Clavell, M. L., Clark, M. M., McAlpine, D. E., \& Jensen, M. D. (2006). Assessment and preparation of patients for bariatric surgery. Mayo Clinic Proceedings, 81, S1l-S17.

Colles, S. L., Dixon, J. B., \& O’Brien, P. E. (2008). Hunger control and regular physical activity facilitate weight loss after laparoscopic adjustable gastric banding. Obesity Surgery, 18, 833-840.

Dillman, D. A.(2000). Mail and internet surveys: The tailored design method. New York: John Wiley \& Sons, Inc.

Elkins, G., Whitfield, P., Marcus, J., Symmonds, R., Rodriguez, J., \& Cook, T. (2005). Noncompliance with behavioral recommendations following bariatric surgery. Obesity Surgery, 15, 546-551.

Field, A. (2009). Discovering statistics using SPSS. Thousand Oaks, CA: Sage Publications Inc. Flegal, K. M., Carroll, M. D., Ogden, C. L., \& Johnson, C. L. (2002). Prevalence and trends in obesity among US adults, 1999-2000. Journal of the American Medical Association, 288, $1723-1727$.

Flum, D. R., Khan, T. V., \& Dellinger, E. P. (2007). Toward the rational and equitable use of bariatric surgery. Journal of the American Medical Association, 298, 1442-1444. 
Frezza, E. E. (2006). Six steps to fast-track insurance approval for bariatric surgery. Obesity Surgery, 16, 659-663.

Gould, J. C., Beverstein, G., Reinbardt, S., \& Garren, M. J. (2007). Impact of routine and longterm follow-up on weight loss after laparoscopic gastric bypass. Surgery for Obesity and Related Diseases, 3, 627-630.

Greenberg, I., Sogg, S., \& Perna, F. M. (2009). Behavioral and psychological care in weight loss surgery: Best practice update. Obesity, 17, 880-884.

Hamilton, M. \& Greenway, F. (2004). Evaluating commercial weight loss programmes: An evolution in outcomes research. Obesity Reviews, 5, 217-232.

Herpertz, S., Kielmann, R., Wolf, A. M., Langkafel, M., Senf, W., \& Hebebrand, J. (2003). Does obesity surgery improve psychosocial functioning? A systematic review. International Journal of Obesity, 27, 1300-1314.

Joyal, S. V. (2004). A perspective on the current strategies for the treatment of obesity. Central Nervous System \& Neurological Disorders, 3, 341-356.

Karlsson, J., Taft, C., Rydén, A., Sjöström, L., \& Sullivan, M. (2007). Ten-year trends in healthrelated quality of life after surgical and conventional treatment for severe obesity: The SOS intervention study. International Journal of Obesity, 31, 1248-1261.

Karmali, S. \& Shaffer, E. (2005). The battle against the obesity epidemic: Is bariatric surgery the perfect weapon? Clinical \& Investigative Medicine, 28, 147-156.

Klem, M. L., Wing, R. R., Chang, C. H., Lang, W., McGuire M. T., Sugerman, H. J., et al. (2000). A case-control study of successful maintenance of a substantial weight loss: Individuals who lost weight through surgery versus those who lost weight through nonsurgical means. International Journal of Obesity, 24, 573-579. 
Lemmens, V., Oenema, A., Klepp, K. I., Henricksen, H. B., \& Brug, J. (2008). A systematic review of the evidence regarding efficacy of obesity prevention interventions among adults. Obesity Reviews, 9, 446-455.

Maggard, M. A., Shugarman, L. R., Suttorp, M., Maglione, M., Sugarman, H. J., Livingston, E. H., et al. (2005). Meta-analysis: Surgical treatment of obesity. Annals of Internal Medicine, 142, 547-559.

McNeill, L. H., Kreuter, M. W., \& Subramanian, S. V. (2006). Social environment and physical activity: A review of concepts and evidence. Social Science and Medicine, 63, 10111022.

Mechanick, J. I., Kushner, R. F., Sugerman, H. J., Gonzalez-Campoy, M., Collazo-Calvell, M. L., Guven, s., et al. (2008). American Association of Clinical Endocrinologists, The Obesity Society, and American Society for Metabolic \& Bariatric Surgery medical guidelines for clinical practice for the perioperative nutritional, metabolic, and nonsurgical support of the bariatric surgery patient. Surgery for Obesity and Related Diseases, 4, S109-S184.

Peacock, J. C. \& Zizzi, S. J. (2011). An assessment of patient behavioral requirements pre- and post-surgery at accredited weight loss surgical centers. Obesity Surgery, Online First. doi: 10.1007/s11695-011-0366-5.

Physical Activity Guidelines Advisory Committee (PAGAC) (2008). Physical Activity Guidelines Activity Committee Report, 2008. Washington, D.C.: U.S. Department of Health and Human Services. 
Perri, M.G. \& Corsica, J. A. (2002). Improving the maintenance of weight lost in behavioral treatment of obesity. In Wadden, T. A. \& Stunkard, A. J. (Eds.), Handbook of obesiry treatment, $1^{\text {st }}$ edition (pp. 357-379). New York: Guilford Press.

Pratt, G. M., McLees, B., \& Pories, W. J. (2006). The ASBS Bariatric Surgery Centers of Excellence program: A blueprint for quality improvement. Surgery for Obesity and Related Diseases, 2, 497-503.

Rowe, B. \& Davis, L. (2007). Bridging the divide between bariatric surgery and traditional weight loss programs. Bariatric Nursing and Surgical Patient Care, 2, 109-112.

Salant, T. \& Santry, H. P. (2005). Internet marketing of bariatric surgery: Contemporary trends in the medicalization of obesity. Social Science \& Medicine 62, 2445-2457.

Sarwer, D. B., von Sydow Green, A., Vetter, M. L., \& Wadden, T. A. (2009). Behavior therapy for obesity: Where are we now? Current Opinion in Endocrinology, Diabetes, \& Obesity, $16,347-352$.

Toussi, R., Fujioka, K., \& Coleman, K. J. (2009). Pre- and postsurgery behavioral compliance, patient health, and postbariatric surgical weight loss. Obesity, 17, 996-1002.

Tucker, J. M., Welk, G. J., \& Beyler, N. K. (2011). Physical activity in U.S. adults: Compliance with the Physical Activity Guidelines for Americans. American Journal of Preventive Medicine, 40, 454-461.

U.S. Food and Drug Administration. (FDA; 2011). FDA expands use of banding system for weight loss. Retrieved from http://www.fda.gov/NewsEvents/Newsroom/PressAnnouncements/ucm245617.htm.

Wadden, T. A. \& Sarwer, D. B. (2006). Behavioral assessment of candidates for bariatric surgery: A patient-oriented approach. Obesity, 14, 53S-62S. 
Wadden, T. A. \& Tsai, A. G. (2006). Bariatric surgery: Crossing a body mass index threshold. Annals of Internal Medicine, 144, 689-691.

Welch, G., Wesolowski, C., Piepul, B., Kuhn, J., Romanelli, J., \& Garb, J. (2008). Physical activity predicts weight loss following gastric bypass surgery: Findings from a support group survey. Obesity Surgery, 18, 517-524.

Wolfe, A. M., Kortner, B., \& Kuhlmann, H. W. (2001). Results of bariatric surgery. International Journal of Obesity, 25, S113-S114.

Worthy, S. L., Lokken, K., Pilcher, K., \& Boeka, A.(2010). Demographic and lifestyle variables associated with obesity. Health Education Journal, 69, 372-380. 
Table 1: Participant demographics

\begin{tabular}{|c|c|c|}
\hline \multirow[t]{2}{*}{ Gender } & Female & $\begin{array}{c}n(\%) \\
360(94.7 \%)\end{array}$ \\
\hline & Male & $20(5.3 \%)$ \\
\hline \multirow[t]{7}{*}{ Race } & White & $336(88.9 \%)$ \\
\hline & Black for African American & $19(5 \%)$ \\
\hline & Hispanic & $14(3.7 \%)$ \\
\hline & Asian & $1(.3 \%)$ \\
\hline & $\begin{array}{l}\text { Native Hawaiian or other Pacific } \\
\text { Islander }\end{array}$ & $1(.3 \%)$ \\
\hline & American Indian or Alaska native & $1(.3 \%)$ \\
\hline & Other & $6(1.6 \%)$ \\
\hline \multirow[t]{7}{*}{ Annual household income } & $\$ 0-19,999$ & $14(3.7 \%)$ \\
\hline & $\$ 20-39,999$ & $41(10.9 \%)$ \\
\hline & $\$ 40-59,999$ & $64(17.1 \%)$ \\
\hline & $\$ 60-79,999$ & $75(20 \%)$ \\
\hline & $\$ 80-99,999$ & $38(10.1 \%)$ \\
\hline & $\$ 100,000$ or greater & $84(22.4 \%)$ \\
\hline & Decline to answer & $59(15.7 \%)$ \\
\hline \multirow[t]{7}{*}{ Education } & Some high school & $1(.3 \%)$ \\
\hline & High school degree & $36(9.7 \%)$ \\
\hline & Some college & 115 (30.9\%) \\
\hline & College degree & $127(34.1 \%)$ \\
\hline & Some graduate work & $20(5.4 \%)$ \\
\hline & Graduate or professional degree & $68(18.3 \%)$ \\
\hline & Other & $5(1.3 \%)$ \\
\hline \multirow[t]{6}{*}{ Marital status } & Married & $267(70.8 \%)$ \\
\hline & Single & $52(13.8 \%)$ \\
\hline & Divorced & $35(9.3 \%)$ \\
\hline & Widowed & $10(2.7 \%)$ \\
\hline & Separated & $7(1.9 \%)$ \\
\hline & Other & $6(1.6 \%)$ \\
\hline \multirow[t]{2}{*}{ Children living in the home } & Yes & $153(41.1 \%)$ \\
\hline & No & 219 (58.9\%) \\
\hline \multirow[t]{5}{*}{ Occupational sedentarism } & Mostly sitting or standing & 254 (67.4\%) \\
\hline & Not currently employed & 43 (11.4\%) \\
\hline & Mostly walking & 38 (10.1\%) \\
\hline & Retired & $36(9.5 \%)$ \\
\hline & $\begin{array}{l}\text { Mostly heavy labor or physically } \\
\text { demanding work }\end{array}$ & $6(1.6 \%)$ \\
\hline
\end{tabular}


Table 2: Participant weight loss demographics

\begin{tabular}{|c|c|c|c|c|c|}
\hline & $n$ & Mean & $\begin{array}{l}\text { Standard } \\
\text { deviation }\end{array}$ & & \\
\hline Age at surgery (years) & 378 & 47.41 & 9.21 & & \\
\hline Weight at surgery (kg) & 380 & 129.51 & 23.80 & & \\
\hline BMI at surgery & 379 & 47.27 & 7.99 & & \\
\hline Time since surgery (months) & 380 & 21.88 & 13.75 & & \\
\hline Current weight (kg) & 379 & 82.35 & 19.20 & & \\
\hline Current BMI & 378 & 30.06 & 6.74 & & \\
\hline Total weight loss (kg) & 379 & 47.21 & 18.45 & & \\
\hline$\%$ weight loss & 379 & 36.11 & 11.08 & & \\
\hline \% excess weight loss & 378 & 70.89 & 22.33 & & \\
\hline \multirow[t]{9}{*}{ Comorbidities } & \multicolumn{2}{|c|}{ Treated before surgery } & $n(\%)$ & Treated after surgery & $n(\%)$ \\
\hline & \multicolumn{2}{|c|}{ High blood pressure } & $244(64.2 \%)$ & High blood pressure & 68 (17.9\%) \\
\hline & \multicolumn{2}{|c|}{ Depression/anxiety } & $198(52.1 \%)$ & Depression/anxiety & $116(30.5 \%)$ \\
\hline & \multicolumn{2}{|c|}{ Sleep Apnea } & 167 (43.9\%) & Sleep Apnea & $32(8.4 \%)$ \\
\hline & \multicolumn{2}{|c|}{ Type-II Diabetes } & $121(31.8 \%)$ & Type-II Diabetes & $27(7.1 \%)$ \\
\hline & \multicolumn{2}{|c|}{ Other disability } & $110(28.9 \%)$ & Other disability & $51(13.4 \%)$ \\
\hline & \multicolumn{2}{|c|}{ Asthma } & $86(22.6 \%)$ & Asthma & $22(5.8 \%)$ \\
\hline & \multicolumn{2}{|c|}{ Binge eating disorder } & $29(7.6 \%)$ & Binge eating disorder & $4(1.1 \%)$ \\
\hline & \multicolumn{2}{|c|}{ Heart disease } & $22(5.8 \%)$ & Heart disease & $8(2.1 \%)$ \\
\hline
\end{tabular}


Table 3: Pre-surgical weight loss attempts

\begin{tabular}{|lcc|}
\hline Weight Watchers & $n$ & (\%) \\
Exercise & 307 & $80.8 \%$ \\
Medication & 286 & $75.3 \%$ \\
Meal replacement/liquid diet & 276 & $72.6 \%$ \\
Low fat diet & 262 & $68.9 \%$ \\
Low carbohydrate/high protein diet & 259 & $68.2 \%$ \\
Behavior modification & 229 & $67.6 \%$ \\
Atkins diet & 222 & $58.4 \%$ \\
Any combination of the listed methods & 152 & $40.0 \%$ \\
Eating plan specific for surgery & 106 & $27.9 \%$ \\
Overeaters Anonymous & 90 & $23.7 \%$ \\
Jenny Craig & 82 & $21.6 \%$ \\
Metabolife & 52 & $13.7 \%$ \\
\hline
\end{tabular}

Table 4: Reported services completed before surgery

\begin{tabular}{|lll|}
\hline & $n$ & (\%) \\
Medical consultation & 377 & $99.2 \%$ \\
Dietary consultation & 351 & $92.4 \%$ \\
Psychological consultation & 349 & $91.8 \%$ \\
Informational seminar & 343 & $90.3 \%$ \\
Attendance at a support group & 247 & $65.0 \%$ \\
Education class & 211 & $55.5 \%$ \\
Multiple lifestyle change classes & 120 & $31.6 \%$ \\
Exercise consultation & 116 & $30.5 \%$ \\
\hline
\end{tabular}


Table 5: Summary of support group leadership

\begin{tabular}{|lrr|}
\hline & $n$ & (\%) \\
Dietitian & 111 & $29.2 \%$ \\
Former patient & 102 & $26.8 \%$ \\
Program coordinator & 88 & $23.2 \%$ \\
Nurse practitioner & 80 & $21.1 \%$ \\
Did not attend support groups & 70 & $18.4 \%$ \\
Physician & 50 & $13.2 \%$ \\
Psychologist & 47 & $12.4 \%$ \\
Exercise professional & 30 & $7.9 \%$ \\
Other & 23 & $6.0 \%$ \\
Licensed professional counselor & 20 & $5.3 \%$ \\
Social worker & 17 & $4.5 \%$ \\
Unknown & 14 & $3.7 \%$ \\
Psychiatrist & 11 & $2.9 \%$ \\
\hline
\end{tabular}

Table 6: Reported services (psychological and behavioral) completed after surgery

\begin{tabular}{|lrc|}
\hline & $n$ & (\%) \\
& & \\
Psychological Services & 86 & $22.6 \%$ \\
Individual counseling & 203 & $53.4 \%$ \\
Group counseling/support group & & \\
Dietary Services & 254 & $66.8 \%$ \\
Consultation & 116 & $30.5 \%$ \\
Individual counseling (3 or more sessions) & 80 & $21.1 \%$ \\
Group classes/counseling & & \\
Exercise Services & 87 & $22.9 \%$ \\
Consultation & 66 & $17.4 \%$ \\
Individual Counseling (3 or more sessions) & 45 & $11.8 \%$ \\
Group sessions & & \\
Lifestyle Services & 135 & $35.5 \%$ \\
Group classes or counseling regarding & & \\
\hline how to change behavior or lifestyle & &
\end{tabular}


Table 7: Frequency of meetings with bariatric professionals

\begin{tabular}{|c|c|c|c|c|c|c|}
\hline $\begin{array}{l}\text { How often have you met with the listed } \\
\text { professional in the } 12 \text { months since surgery? }\end{array}$ & $\begin{array}{c}0 \\
\text { times }\end{array}$ & $\begin{array}{l}1-3 \\
\text { times }\end{array}$ & $\begin{array}{c}4-6 \\
\text { times }\end{array}$ & $\begin{array}{l}7-9 \\
\text { times }\end{array}$ & $\begin{array}{l}10 \text { or } \\
\text { more } \\
\text { times }\end{array}$ & $\begin{array}{c}\text { Not } \\
\text { applicable }\end{array}$ \\
\hline Surgeon & $\begin{array}{l}6.6 \% \\
(24)\end{array}$ & $\begin{array}{l}52.6 \% \\
(192)\end{array}$ & $\begin{array}{l}25.8 \% \\
(94)\end{array}$ & $\begin{array}{l}7.9 \% \\
(29)\end{array}$ & $\begin{array}{l}5.5 \% \\
(20)\end{array}$ & $\begin{array}{l}1.6 \% \\
(6)\end{array}$ \\
\hline Nurse/Physician assistant & $\begin{array}{l}23.0 \% \\
(75)\end{array}$ & $\begin{array}{l}36.8 \% \\
(120)\end{array}$ & $\begin{array}{l}20.9 \% \\
(68)\end{array}$ & $\begin{array}{l}4.6 \% \\
(15)\end{array}$ & $\begin{array}{l}7.1 \% \\
(23)\end{array}$ & $\begin{array}{l}7.7 \% \\
(25)\end{array}$ \\
\hline Dietitian & $\begin{array}{l}27.4 \% \\
(93)\end{array}$ & $\begin{array}{l}47.2 \% \\
(160)\end{array}$ & $\begin{array}{l}13.9 \% \\
(47)\end{array}$ & $\begin{array}{l}2.1 \% \\
(7)\end{array}$ & $\begin{array}{l}3.8 \% \\
(13)\end{array}$ & $\begin{array}{l}5.6 \% \\
(19)\end{array}$ \\
\hline $\begin{array}{l}\text { Psychologist or other mental health } \\
\text { professional }\end{array}$ & $\begin{array}{l}56.5 \% \\
(183)\end{array}$ & $\begin{array}{l}21.3 \% \\
(69)\end{array}$ & $\begin{array}{l}4.6 \% \\
(15)\end{array}$ & $\begin{array}{l}1.5 \% \\
(5)\end{array}$ & $\begin{array}{l}9.6 \% \\
(31)\end{array}$ & $\begin{array}{l}6.5 \% \\
(21)\end{array}$ \\
\hline Exercise professional & $\begin{array}{l}52.7 \% \\
(176)\end{array}$ & $\begin{array}{l}18.6 \% \\
(62)\end{array}$ & $\begin{array}{l}7.2 \% \\
(24)\end{array}$ & $\begin{array}{l}3.3 \% \\
(11)\end{array}$ & $\begin{array}{l}9.9 \% \\
(33)\end{array}$ & $\begin{array}{l}8.4 \% \\
(28)\end{array}$ \\
\hline
\end{tabular}

Table 8: Summary of satisfaction with services

\begin{tabular}{|lrrr|}
\hline & $n$ & Mean & $\begin{array}{r}\text { Standard } \\
\text { deviation }\end{array}$ \\
$\begin{array}{l}\text { Initial satisfaction with surgery* } \\
\text { (3 months post-surgery) }\end{array}$ & 379 & 4.46 & 1.02 \\
Overall current satisfaction with surgery* & 380 & 4.54 & .95 \\
Satisfaction with psychological services* & 347 & 3.39 & 1.46 \\
Satisfaction with support group experience* & 324 & 3.54 & 1.33 \\
Satisfaction with dietary services* & 372 & 3.38 & 1.41 \\
Satisfaction with exercise services* & 186 & 2.89 & 1.49 \\
Total satisfaction with services^ & 163 & 13.77 & 4.39 \\
\hline
\end{tabular}

*scale 1-5; ^scale 4-20 
Table 9: Summary of perceived impact of surgery ratings

\begin{tabular}{|lcc|}
\hline & Mean & $\begin{array}{c}\text { Standard } \\
\text { deviation }\end{array}$ \\
3 months before surgery: & -.04 & 1.19 \\
Mental health^ & -.98 & 1.01 \\
Physical health^ & 3.83 & 1.14 \\
Eating habits* & & \\
Impact of surgery on: & 1.21 & .98 \\
Mental health - 3 months after surgery^^ & 1.47 & .94 \\
Mental health - currently^ & 1.41 & .82 \\
Physical health - 3 months after surgery^^ & 1.75 & .70 \\
Physical health - currently^ & 1.39 & .72 \\
Eating habits - 3 months after surgery* & 1.56 & .78 \\
Eating habits - currently* & 1.79 & .87 \\
\hline Physical activity levels* & &
\end{tabular}

^-2 to 2 scale; $* 1$ to 5 scale 
Table 10: Summary of participant physical activity behaviors

\begin{tabular}{|c|c|c|c|c|}
\hline & Mean & $\begin{array}{l}\text { Standard } \\
\text { deviation }\end{array}$ & $n$ & $\%$ \\
\hline \multicolumn{5}{|l|}{ Before surgery } \\
\hline Days of moderate physical activity & 1.63 & 1.73 & & \\
\hline Minutes of moderate physical activity & 29.02 & 24.79 & & \\
\hline Total minutes of moderate physical activity per week & 60.93 & 119.91 & & \\
\hline Days of vigorous physical activity & .54 & 1.04 & & \\
\hline Minutes of vigorous physical activity & 21.79 & 32.75 & & \\
\hline Total minutes of vigorous physical activity per week & 21.70 & 54.34 & & \\
\hline Meeting guidelines for physical activity & & & 65 & $17 \%$ \\
\hline \multicolumn{5}{|l|}{ After surgery } \\
\hline Days of moderate physical activity & 3.82 & 2.00 & & \\
\hline Minutes of moderate physical activity & 42.63 & 33.10 & & \\
\hline Total minutes of moderate physical activity per week & 188.89 & 212.12 & & \\
\hline Days of vigorous physical activity & 2.19 & 2.04 & & \\
\hline Minutes of vigorous physical activity & 41.73 & 33.36 & & \\
\hline Total minutes of vigorous physical activity per week & 110.43 & 151.09 & & \\
\hline Meeting guidelines for physical activity & & & 236 & $62 \%$ \\
\hline
\end{tabular}

Table 11: Summary of participant dietary behaviors

\begin{tabular}{|c|c|c|c|c|}
\hline & Mean & $\begin{array}{l}\text { Standard } \\
\text { deviation }\end{array}$ & $n$ & $\%$ \\
\hline Daily fruit servings & 1.49 & 1.05 & & \\
\hline Daily vegetable servings & 2.15 & 1.20 & & \\
\hline Combined fruit and vegetable servings & 3.65 & 1.84 & & \\
\hline Meeting guidelines for fruits and vegetables & & & 78 & $20.5 \%$ \\
\hline
\end{tabular}


Table 12: Summary of exposure to behavioral modification principles

\begin{tabular}{|lcc|}
\hline & $n$ & (\%) \\
Dietary & & \\
Keeping a daily food journal & 325 & $86.7 \%$ \\
$\begin{array}{l}\text { Identifying and planning for barriers } \\
\text { to healthy eating }\end{array}$ & 290 & $77.7 \%$ \\
$\begin{array}{l}\text { Finding support for healthy eating } \\
\text { Exercise Services }\end{array}$ & 279 & $75.6 \%$ \\
$\begin{array}{l}\text { Finding support for maintaining exercise } \\
\text { habits }\end{array}$ & 179 & $47.3 \%$ \\
$\begin{array}{l}\text { Identifying and planning for barriers } \\
\text { to exercise }\end{array}$ & 173 & $47.0 \%$ \\
Keeping a daily exercise journal & 167 & $45 . \%$ \\
Lifestyle Services & & \\
Finding support for a healthy lifestyle & 221 & $62.1 \%$ \\
Identifying and planning for barriers & 212 & $58.1 \%$ \\
To healthy living & & \\
Setting effective goals & 212 & $57.8 \%$ \\
Controlling negative thoughts & 172 & $47.1 \%$ \\
\hline
\end{tabular}


Table 13: Summary of response to use of potential service

If regular psychological counseling had been available to you at your

$n$

(\%)

bariatric facility throughout the surgical experience, would you have used this service?

Yes, but only if included in services.

Yes, and I would be willing to pay additional

$56 \quad 15.0 \%$

out-of-pocket cost.

This service was available to me during my surgical experience

$39 \quad 10.4 \%$

and I did use the service.

No, I would not use this service.

$71 \quad 19.0 \%$

This service was available at my facility and I did NOT

use the service.

If a program had been available to you at your bariatric facility to help you change your lifestyle and behavior, would you have attended?

Yes, but only if included in services.

Yes, and I would be willing to pay additional

out-of-pocket cost.

This service was available to me during my surgical experience and I did use the service.

No, I would not use this service.

This service was available at my facility and I did NOT 


\section{APPENDIX A: Review of Literature}

The following will review literature in the areas of: a) the use and efficacy of behavioral modification in the treatment of obesity; b) the use and efficacy of bariatric surgery in the treatment of obesity; c) the use and efficacy of behavioral modification and bariatric surgery in combination; and d) summary and critique of the literature.

Recent estimates conclude that approximately 400 million adults across the globe qualify as obese (body mass index $[\mathrm{BMI}] \geq 30 \mathrm{~kg} / \mathrm{m}^{2}$ ), thus contributing to the classification of obesity as one of the leading causes of preventable death (Lemmens et al., 2008). The prevalence of obesity in the United States has more than doubled in the last 25 years, and the fastest growing population of obese individuals are those categorized as extremely obese (BMI $\geq 40 \mathrm{~kg} / \mathrm{m}^{2}$ ) (Bachman, 2007). Obesity results in a number of significant consequences to both the individual and society at large. For instance, associated health risks include hypertension and cardiovascular disease, type-II diabetes, osteoarthritis, and some cancers (Cerulli \& Malone, 1998). In addition, individuals who are obese report a lower quality of life, including increased rates of prejudice and discrimination, and greater levels of physical impairment (Herpertz, Kielmann, Wolf, Langkafel, Senf, \& Hebebrand, 2003; Joyal, 2004). Obesity also contributes to increased health care costs, decreased productivity, and higher rates of sick leave, all of which create a negative economic impact in the billions of dollars every year (Bachman, 2007; Cerulli \& Malone).

The most severe repercussion of obesity is death, as approximately 300,000 adults die each year due to obesity-related complications (Mokdad et al., 2003). Many of these deaths are attributable to lifestyle factors, including poor dietary habits and sedentary behaviors. The term “sedentary death syndrome" was created to describe a set of lifestyle-mediated disorders resulting in mortality, including obesity, cardiovascular disease, and type-II diabetes (Booth \& 
Chakravarthy, 2002). Considering that about $51 \%$ of Americans do not meet nationally recommended guidelines for physical activity, it is not surprising that increasingly sedentary lifestyles are contributing to both higher obesity rates and mortality rates (Haskell et al, 2007).

Given the prevalence of obesity and the myriad negative outcomes related to being overweight or obese, it is not surprising that significant numbers of men $(25 \%)$ and women $(30 \%)$ attempt to lose weight each year (Hamilton \& Greenway, 2004). Methods for weight loss vary, and include management of diet and activity behaviors, pharmacological treatment, and surgical procedures. However, Douketis, Macie, Thabane, and Williamson (2005) posited that obesity is a chronic disease, and thus weight regain is common with cessation of treatment. Therefore, researchers recommend behavioral modification be included in weight management programs in order to enhance the likelihood of permanent lifestyle change and long-term weight loss maintenance (Volek, Van Heest, \& Forsythe, 2006).

\section{The Use and Efficacy of Behavioral Modification in the Treatment of Obesity}

Obesity is thought to be a complex disease influenced by societal, environmental, and genetic factors; however, an imbalance between energy consumption and energy expenditure remains an important regulatory mechanism for weight maintenance (Cerulli \& Malone, 1998;

Lemmens et al, 2008). The two primary factors that can be modified to encourage weight loss are food intake and physical activity, and thus the first line of treatment for obesity has traditionally been behavioral changes to lifestyle habits.

Behavioral management for the treatment of obesity first gained popularity in the 1950's with the application of principles of psychoanalytic theory to weight loss. During this time it was commonly believed that obesity was a symptom of underlying psychological disorder, and thus treatment focused on developmental and personality issues (Levy, Finch, Crowell, Talley, \& 
Jeffery, 2007). However, as psychoanalytic therapies were proven ineffective for promoting weight loss, increased importance was placed on the role that the environment plays in weight status. Principles of learning theory and classical conditioning were incorporated into obesity management starting in the 1960's in order to help patients manage external stimuli and reinforcements related to diet and exercise (Karmali \& Shaffer, 2005; Levy et al., 2007).

Since behavioral therapies were first implemented, treatment durations have increased from about 10 weeks, to 30 weeks on average; the average patient weight loss has also tripled during this time to about $10 \%$ of initial body weight (Jones; Wadden \& Butryn, 2003; Sarwer, Green, Vetter, \& Wadden, 2009). While such results may seem small, weight loss of this magnitude is recognized by the World Health Organization (WHO) as contributing to significant health benefits (WHO, 1998). In addition, some research has indicated that around 66\% of weight losses are maintained at one year following behavioral therapy (Foreyt \& Goodrick, 1993).

Behavioral therapy programs help clients modify diet and exercise behaviors through skill acquisition, enhancement of motivation, and improved support (Kushner, 2005). Behavioral therapy places emphasis on long-term control of lifestyle behaviors, both through improved awareness of individual factors that affect weight status as well a better understanding of the impact of the individual's interaction with his environment (Melin et al., 2003). Patients are encouraged to manage their environment by increasing stimuli that promote and reinforce healthy eating and physical activity behaviors and decrease cues that promote sedentary and negative health habits (Levy et al., 2007; Smith \& Wing, 2000). While strategies that are utilized in treatment may vary, common components of behavioral modification programs include selfmonitoring, goal-setting, stimulus control, cognitive restructuring, relapse prevention, social 
support, and contingency management (Eckel, 2008; Kushner, 2005; Levy et al., 2007; Smith \& Wing, 2000).

Self-monitoring is widely recognized as one of the cornerstones of successful weight management, and can include daily recording of food behaviors, exercise, and weight status (Levy et al., 2007; Smith \& Wing, 2000). The purpose of self-monitoring is to help increase patients' awareness of their own behavior in order to identify patterns and environmental stimuli that can be changed. Recording may include time, type of food consumed or activity completed, environmental setting, and any potential psychosocial correlates, such as mood, that might influence behavior (Levy et al; Smith \& Wing, 2000).

Use of self-monitoring strategies has been identified as a major contributor to successful weight loss outcome (Sarwer \& Wadden, 1999); for example, individuals recognized for losing and maintaining significant weight loss through the National Weight Control Registry indicated regular weigh-in as a helpful tool for weight management (Butryn, Phelan, Hill, \& Wing, 2007). In addition, one study of individuals in a behavioral weight loss program $(n=40)$ found that those participants who consistently recorded exercise behaviors were more likely to exercise $(r=$ $.52, p<.01)$ and lose weight $(r=.44, p<.05)$ (Carels et al., 2005). Another benefit of selfmonitoring is that it allows patients to track progress towards both short and long-term goals, which may enhance adherence to behavioral changes (Levy et al., 2007).

Helping patients set or modify goals for weight loss has been recognized as an important facet of treatment, as many individuals attempting to lose weight set unrealistic or lofty goals. The "False Hope Syndrome" has been identified as a pattern of recurrent processes that occur as individuals struggle to make behavioral changes (Polivy \& Herman, 2002). A primary component of False Hope Syndrome is the setting of unrealistic goals; failure to reach these 
goals is likely to occur, and individuals then make faulty attributions (such as that the approach utilized for change was too hard) for these failures in order to justify renewed attempts at change in the future. The end result is that most individuals will attempt change at least 5-6 times before success is experienced (Polivy \& Herman, 2002).

Goal setting techniques can therefore be utilized to help patients through the process of self-change more effectively by aiding them in the creation of realistic and perhaps modest weight loss goals. Previous research has indicated that when participants are not able to reach specific goals they express dissatisfaction with weight loss, even when this loss is sufficient enough for health benefits to be experienced; it is likely that this dissatisfaction could be a factor behind weight regain later on (Foster, Wadden, Vogt, \& Brewer, 1997; Smith \& Wing, 2000).

Principles of effective goal setting that are often reinforced to patients include setting specific and small goals; explicit, measureable, time-bound goals allow for clarity in determination as well as enhanced problem solving, while small short-term goals provide increased opportunity for success, which is likely to influence self-efficacy, motivation, and adherence (Jones, Harris, Waller, \& Coggins, 2005; Jones, Wilson \& Wadden, 2007; Levy et al, 2007). In addition, patients can be encouraged to set goals related to various aspects of weight loss, including calorie intake and physical activity, as well as for controlling environmental stimuli in order to create an atmosphere conducive to weight loss (Levy et al.).

Stimulus control involves changing one's surrounding environment in order to increase cues that promote positive health behaviors, such as eating in moderation and regular exercise, while also decreasing cues that trigger unhealthy habits such as overeating or sedentary activities (Levy et al., 2007; Smith \& Wing, 2000). Modifications to the environment should be individualized depending on the patient; however, common strategies include removing 
temptations such as snack foods, restricting eating to certain rooms, and avoiding high-risk venues such as fast food restaurants (Foreyt \& Poston, 1998; Jones, Wilson, \& Wadden, 2007). In addition, prompts can be used in order to promote increased physical activity, such as through telephone or e-mail contact, and to improve motivation and compliance (Foreyt \& Poston, 1998). For example, one study of 135 participants in a walking program found that weekly telephone prompts were more successful at increasing walking adherence than calls made once every three weeks $(\mathrm{LD}(1)=17.719, p<.0001)($ Lombard, Lombard, \& Winett, 1995).

Enhancing patients' perceptions of their control of the environment is a particularly important component of behavioral treatment in current American society. The terms "obesogenic" and "toxic environment" are often used to describe American lifestyles where consumption of large servings of high fat foods is encouraged while physical activity is tacitly discouraged due to increased participation in sedentary work and leisure activities (Brownell \& Horgen, 2003). Therefore, helping patients to monitor and modify the environment in order to foster healthy habits may improve the potential for long-term successful weight maintenance (Foreyt \& Poston, 1998).

The individual's internal environment is another concern for some obese patients. Cognitive strategies such as restructuring irrational belief patterns and managing negative emotions and thoughts related to eating and physical activity are another common component of many behavioral modification programs (Levy et al., 2007; Smith \& Wing, 2000). Some patients may exhibit negative or self-defeating thoughts related to their weight or themselves, and thus cognitive restructuring is taught to patients so that they may actively begin to challenge and replace such thoughts (Foreyt \& Poston, 1998). A common irrational belief pattern often demonstrated by individuals attempting weight loss is polarized, or "all-or-none" thinking; for 
example, if a lofty goal of a fifty pound weight loss is not achieved, a more realistic loss of ten pounds is perceived as a failure. Another typical irrational belief pattern is generalization, in which future predictions about behavior are based on one previous incident. For example, a patient may think that giving in to a temptation indicates that they cannot be successful at any weight loss attempts (Levy et al.).

Patients may be asked to self-monitor their thoughts and feelings in order to identify irrational belief patterns or environmental cues that trigger negative thoughts. Once maladaptive thinking styles or habits are recognized, techniques from cognitive behavioral therapies such as reframing and countering can be used to help facilitate thinking that is more conducive to promotion of healthy behaviors and weight loss (Levy et al., 2007). Cognitive strategies can also be used to build self-acceptance and self-esteem in patients; past research has shown that improved self-esteem predicts weight loss maintenance after intervention cessation (Nir \& Neumann, 1995), and thus increasing positive self-beliefs could be beneficial for improving long-term adherence.

Assisting patients in maintaining healthy habits and adhering to behavioral changes over time is a critical component of lifestyle modification programs. Maintaining rational beliefs and realistic expectations is but one tool that patients can use to help prohibit reversion back to unhealthy behaviors. Relapse prevention emphasizes training patients to recognize situations that might be "high-risk" for management of new behaviors, and are often adapted from the addictions field (Foreyt \& Poston, 1998; Levy et al., 2007; Perri et al., 2001). Once patients are cognizant of environments or situations that could threaten maintenance of health behaviors, strategies can be developed for how to avoid or manage these scenarios. Relapse is common in behavior change, and thus normalizing setbacks or "slips" is a proactive approach for 
overcoming potential guilt or negative emotion; being prepared for potential temptations will also allow patients to better handle stress and build self-efficacy, two things associated with increased progression through behavioral stages of change (Prochaska \& Velicer, 1997). One period of time considered "high-risk" for weight management is the holidays; thus, strategies such as consistent self-monitoring and identifying social support systems can be helpful for adhering to diet and activity patterns (Baker \& Kirschenbaum, 1998).

Patients who perceive higher levels of social support are more likely to experience success in weight management programs (Foreyt \& Poston, 1998; Levy et al., 2007). Support can involve the inclusion of significant others and family members in treatment (Black, Gleser, \& Kooyers, 1990), or assertiveness training that will facilitate patients' communication with family and friends (Smith \& Wing, 2000). Family systems often change after significant weight loss by a family member, as others may face difficulty adapting to changes within the individual patient; therefore, it is important to address family dynamics with patients in order to evaluate their support network (Marcus \& Elkins, 2004).

Peer support groups are another viable option for providing support in behavioral modification programs. Peer support groups provide an open forum for patients who have undergone similar experiences to share relevant emotional responses, manage stress, and generate coping skills and alternative health behaviors (Marcus \& Elkins, 2004). In addition, support groups for bariatric patients can foster increased self-acceptance and interpersonal relationships that were not previously available to patients prior to surgery (Foreyt \& Poston, 1998). Relationships that can provide further support for healthy behaviors include those involving professionals in the bariatric field. Long-term success at weight maintenance is more likely to occur with continued care (Jones, Wilson, \& Wadden, 2007). In one study analyzing the 
effects of support group participation patients $(n=78)$ rated continuing care as the most valued aspect of overall treatment; in addition, participants who attended support groups for longer than five months lost significantly more weight at 9 and 12 months $(p<.05)$ than participants who attended for fewer than five months (Song, Reinhardt, Buzdon, \& Liao, 2008).

Research has also shown that patients who receive long-term provider care via telephone and e-mail contact are more likely to maintain weight losses (Perri, Shapiro, Ludwig, Twentyman, \& McAdoo, 1984; Wadden, Butryn, \& Byrne, 2004). For instance, Perri et al. found that continued therapist contact, either by telephone or regular mail, enhanced weight loss maintenance when compared to no further intervention. Tate, Wing, and Winett (2001) found that more participants $(n=33)$ in a treatment program consisting of weekly contact and individualized feedback via e-mail met a 5\% weight loss goal (45\%) than participants $(n=32)$ who received only access to an educational website $(22 \% ; p=.05)$.

However, while internet-based programs may have the ability to reach millions, research shows that on-site treatment is typically more effective. Harvey-Berino et al. (2002) examined weight loss maintenance among participants assigned to either a therapist-led intervention $(\mathrm{n}=$ 14), internet-based intervention $(n=15)$, or control group $(n=15)$. The authors found no significant differences among the three groups for total weight loss; however, participants in the therapist-led group reported higher attendance at treatment meetings than the internet-based group $(58 \pm 22 \%$ vs. $33 \pm 23 \%, p<.005)$ and greater satisfaction with treatment, factors that may contribute to greater long-term adherence. Therefore, overall research indicates that support groups provided on-site and facilitated by a mental health professional are likely most effective for promoting weight loss maintenance. 
Another component of many behavioral modification programs is contingency management or reinforcement. Weight loss can be inherently reinforcing due to improved appearance, compliments from others, and decreased health risks; however, over time as weight loss plateaus, motivation to continue can wane (Levy et al., 2007). Positive reinforcement can be used to enhance motivation in weight management with encouragement or rewards for small positive behavior changes. Rewards that are typically recommended include material goods, such as new clothes, or pleasant activities (Levy et al.). In some cases monetary rewards have been utilized; however, while monetary rewards may serve to increase extrinsic motivation, when removed they may not promote long-term maintenance of behavior change (Jeffrey \& Wing, 1995). Instead, a focus on building intrinsic motivation may improve adherence, and can be done by helping patients to focus on the rewards provided by the process of health habits such as exercise, including improved physiological and affective states (Kimiciek, 2002). Overall, the use of contingency management strategies is recommended for patients who are initiating health behavior change, while promotion of intrinsic reinforcers is a helpful strategy for improving long-term adherence (Lox, Martin Ginis, \& Petruzzello, 2006).

All of the aforementioned techniques and strategies are commonly used in behavioral modification programs for weight loss, with the primary goal being to shape health behaviors in such a way that energy consumption is decreased and energy expenditure is increased. Thus, the overarching behaviors that are targeted for change are physical activity and diet, and the components of behavioral modification programs are meant to support patients in adopting and maintaining changes in these areas. Therefore, some programs may include psychoeducation or counseling regarding improved nutrition and incorporation of lifestyle activities. 
Nutritional education may include information on how to read food labels, as well as discussion of strategies for modifying popular recipes or eating healthy in restaurants or social situations (Smith \& Wing, 2000). Some basic recommendations may be given, including decreasing fat content and increasing consumption of complex carbohydrates and fiber, though qualification for providing such guidelines should be considered before dietary consultation (Eckel, 2008; Hainer, Toplak, \& Mitrakou, 2008). In addition, some behavioral modification programs utilize meal replacements such as shakes as a tool to reduce calorie intake and manage environmental stimuli by limiting choices and reducing temptation (Levy et al., 2007).

Education may also be provided regarding prescription for physical activity based on nationally recognized guidelines (ACSM, 2000). Increasing levels of physical activity is one of the most important facets of behavioral modification programs, not just because exercise helps to create energy deficits, but also because of the myriad benefits that physical activity affords outside of weight control and improved fitness. Regular exercise is correlated with improvements in cardiovascular health and other co-morbidities often found in obese patients, and also improves mental health and well-being (Hainer et al., 2008).

Resulting improvements in psychological factors such as body image and self-esteem may even buffer the stress response for some patients, and increase effective coping for situations that provoke negative behaviors such as overeating (Foreyt \& Poston, 1998). Therefore, promotion of lifestyle physical activity, or the incorporation of exercise through common tasks of daily living (i.e., parking one's car further away from buildings, using stairs instead of elevators, etc.), is recommended for improving the likelihood of long-term weight loss maintenance, particularly for patients who report a dislike of exercise or barriers related to a lack of perceived time (Andersen et al., 1999; Wadden, Butryn, \& Byrne, 2004). 
The single best predictor of long-term weight loss maintenance is increased physical activity (Jones, Wilson, \& Wadden, 2007; Welch et al., 2007). Research supports a doseresponse relationship between exercise and weight loss, such that patients who exercise for greater duration often experience improved weight losses (Smith \& Wing, 2000); members of the National Weight Control Registry, who have been identified on average as losing $32.4 \mathrm{~kg}$ and maintaining this loss for 5.5 years, report exercising at a high level (Klem, Wing, McGuire, Seagle, \& Hill, 1997). However, physical activity does not need to be completed in a programmed manner, nor must duration be continuous for health benefits to occur, as previous studies have indicated that exercise can be accumulated in short-term "bouts" throughout the day (Jakicic, Winters, Lang, \& Wing, 1999). Helping patients to fit physical activity into their existing lifestyle through behavioral modification is an important step in facilitating weight loss, and improves the likelihood that patients will be adherent to both exercise and weight management in the long run.

Regardless of what specific topical components are included in treatment, empirical reviews have determined similar characteristics of programs that incorporate behavioral therapy. Behavioral modification programs utilized in weight management typically last between 16-26 weeks, with patients attending weekly sessions (Jones et al., 2007; Wadden, Butryn, \& Byrne, 2004). A group format is often implemented, though individual sessions may be completed in order to explore patients' self-monitoring records or personal barriers to change (Wadden, Butryn, \& Byrne, 2004); in addition, personal counseling is often preferred for severely obese individuals and for men (Hainer et al., 2008). However, while individual sessions may be beneficial, group settings are more cost effective and were found to induce increased weight loss 
among participants $(n=75)$ in at least one study (Wilks's $\lambda=.856, F(2,53)=4.47, p=.016, \eta^{2}=$ .14) (Renjilian et al., 2001).

An average group in hospital or university settings is likely to have around 10-20 participants, and sessions are usually between 60 and 90 minutes in duration (Jones et al, 2007; Smith \& Wing, 2000; Wadden, Butryn, \& Byrne, 2004). Sessions may be facilitated by various members of a multidisciplinary team, including registered dieticians, psychologists, exercise physiologists, and other health professionals. A structured format is usually followed and different topics presented for discussion related to improving adherence to behavioral changes; homework assignments may also be assigned in order to help patients practice strategies and assimilate new behaviors into their existing lifestyles (Jones et al.; Smith \& Wing, 2000; Wadden, Butryn, \& Byrne, 2004).

Research has shown that about $80 \%$ of patients who begin behavioral modification programs complete them, with an average weight loss of about 8-9 kilograms (18-20 pounds) within a six month time period (Jones et al., 2007; Smith \& Wing, 2000). A weight loss of this size (generally about $7-10 \%$ of initial body weight) may confer positive health benefits, including improvement of blood pressure and diabetes status (Sarwer, von Sydow Green, Vetter, \& Wadden. 2009). The Diabetes Prevention Program examined the effects of placebo, pharmacological treatment, and behavioral modification on 3,200 overweight and obese participants. After an average treatment duration of 2.8 years, individuals in the behavioral modification group lost $5.6 \mathrm{~kg}$ and decreased their risk of progression to type-II diabetes by $58 \%$, compared to a $31 \%$ decreased risk and $2.1 \mathrm{~kg}$ weight loss for participants in the pharmacological group (Orchard et al., 2005). Unfortunately, about half of this weight loss was regained by participants within a 4-year span on average. 
It is not uncommon for patients in any weight loss intervention to experience weight regain. On average, patients in behavioral modification programs regain about $30-35 \%$ of weight lost within a year of treatment, and half of patients are likely to return to baseline weight after five years (Sarwer et al., 2009). Overall, only 5-10\% of patients will maintain weight loss for more than a few years (Karmali \& Shaffer, 2005). Therefore, while the efficacy of behavioral management for promotion of weight loss in the short-term has been well established, long-term maintenance remains a major problem. Making changes to diet and physical activity behaviors can be difficult, but is crucial to weight maintenance; many individuals require intensive support in order to successfully integrate such changes into their existing lifestyle. One explanation for why behavioral modification programs may continually fall short is the brief nature of treatment; obesity is widely recognized as a chronic disease, and thus increasing the duration of programs is one step towards promotion of long-term care that may increase weight loss maintenance (Wadden, Butryn, \& Byrne, 2004). Future research should continue to explore how behavioral modification programs can be improved, such as by increasing treatment length, in order to maximize outcomes.

Because of the limited effectiveness of behavioral modification programs for long-term maintenance, new strategies for weight loss continue to be explored. Pharmacological treatments are often utilized as a second-line approach; however, high weight regain after medication is discontinued has been documented (Bray, 2001). Bariatric surgery, or surgery to the upper gastrointestinal system, continues to gain in popularity as a method for inducing sustained weight loss among the severely obese (Karmali \& Shaffer, 2005). 


\section{The Use and Efficacy of Bariatric Surgery in the Treatment of Obesity}

Bariatric surgery continues to grow in popularity as a treatment for severe or morbid obesity; thus, it is typically reserved for patients with a BMI $\geq 40 \mathrm{~kg} / \mathrm{m}^{2}$. Three types of bariatric surgery exist: malabsorptive, restrictive, and a combination of the previous two types (Smith, 2005). Jejuno-ileal bypass, a malabsorptive procedure, was the first bariatric surgery to gain popularity in the 1960's and 1970's (Elder \& Wolfe, 2007; Karmali \& Shaffer, 2005). In malabsorptive procedures such as jejuno-ileal bypass, the small intestine is excluded from the digestive tract, thus creating malabsorption of most nutrients and effective weight loss. However, malabsorption also leads to nutritional deficiencies, electrolyte imbalances, and frequent diarrhea, which is why jejuno-ileal bypass is no longer recommended. Instead, gastric stapling and laparoscopic procedures are now common due to the decreased adverse effects and increased safety of such methods (Elder \& Wolfe, 2007; Karmali \& Shaffer, 2005; Smith, 2005).

Gastric restrictive procedures primarily limit food intake and do not interfere with normal digestive functioning (Karmali \& Shaffer, 2005). Restrictive procedures typically reduce the size of the stomach, thus prohibiting patients from being able to consume large amounts of food and inducing early satiety. Three types of restrictive or combination procedures are commonly performed: vertical banded gastroplasty (VBG); adjustable gastric banding (AGB); and Roux en Y gastric bypass (RYGB).

In vertical banded gastroplasty (VBG) the stomach is stapled front to back below the gastro-esophageal junction, which creates a hole. A 1-cm wide band is then placed at the opening between the upper gastric pouch and the body of the stomach, also known as the stoma (Elder \& Wolfe, 2007). The band mechanically restricts food intake, thus limiting energy consumption. While VBG became popular in the 1980's, it is not commonly utilized today due to associated 
complications and often ineffective weight loss maintenance. Patients who undergo VBG may suffer from progressive intolerance of gastric constriction, exhibited as vomiting, gastroesophageal reflux, and ulcers. Negative reaction to an internal foreign object (the band) can lead to chronic inflammation and scarring, and incisional hernia may occur as well (Elder \& Wolfe, 2007; Karmali \& Shaffer, 2005).

Adjustable gastric banding (AGB) is a more contemporary bariatric surgical approach. AGB utilizes laparoscopic surgical techniques in order to insert a silicone gastric band at the upper end of the stomach. This band creates a gastric pouch that will hold approximately 30 milliliters. Connected to the band is a subcutaneous port; saline solution can be injected into the band through this port in order to achieve a constriction of the gastric pouch and increased satiety. The band can thus be adjusted individually in order to improve weight loss outcomes. Early operative risks must be considered with AGB, including splenic and esopahgeal injury; however, further complications are similar to those experienced with VBG and are considered to be less common and less severe in comparison (Elder \& Wolfe, 2007; Karmali \& Shaffer, 2005).

Gastric bypass procedures were popularized in the 1970's and initially consisted of a horizontal partitioning of the stomach in order to create a gastric pouch; gastrointestinal continuity is then established by utilizing a loop of jejunum (the middle section of the small intestine). Bile reflux was often experienced with the loop procedure, which led to the increased use of Roux en Y reconstruction of continuity instead (Elder \& Wolfe, 2007). Roux en Y gastric bypass (RYGB) also constructs a small gastric pouch using stapling across the stomach, but creates a Roux en Y limb from a segment of the small intestine that empties into the jejunum (Karmali \& Shaffer, 2005). Various lengths of intestine have been used to form the Roux en Y limb in an attempt to maximize weight loss, and include the biliopancreatic limb, the alimentary 
limb, and the common channel (Elder \& Wolfe, 2007). RYGB is considered a combination approach as it is both restrictive and malabsorptive; malabsorption occurs due to the bypass of the stomach, duodenum, and jejunum. Thus, complications include vitamin deficiencies, hypocalcemia and anemia, as well as surgical risks including leak and Roux en Y obstruction. Despite these potential negative consequences, RYGB has been shown to produce more significant and sustained weight loss than VBG and gastric bypass (Karmali \& Shaffer, 2005).

Other bariatric procedures exist but are not as commonly implemented as those discussed previously. These include the malabsorptive procedures known as biliopancreatic diversion and biliopancreatic diversion with duodenal switch. Through these procedures a larger gastric pouch is created (about 200 milliliters), but the biliopancreatic limb is bypassed, thus limiting fat absorption. While these procedures can facilitate greater weight loss than those experienced with gastric restriction, and are preferable to jejuno-ileal bypass, nutrient deficiencies and other gastric abnormalities are common (Karmali \& Shaffer, 2005).

All bariatric surgical procedures come at some risk, and up to $20 \%$ of patients require additional surgery in order to correct problems such as internal bleeding or leakage (Smith, 2005). Common complications include the development of ulcers, hernias, and gallstones. In addition, research has shown a risk of mortality of between $.33 \%$ and $2 \%$. Certain factors have been identified that increase the risk of death, including higher pre-surgical BMI, age $>60$, male gender, and comorbidities like hypertension and cardiovascular disease (Elder \& Wolfe, 2007). However, despite some risk, research has indicated that long-term survival is higher for patients following bariatric surgery than for matched morbidly obese control patients who do not have surgery (Christou et al., 2004). 
Research also supports the overall efficacy of weight loss surgery. Meta-analysis of 136 studies including a total of 22, 094 participants found mean (95\% confidence interval) significant excess weight loss at the outcome time point when comorbidities were assessed was indicated for gastric banding $(47.5 \% ; p<.001)$, gastric bypass $(61.6 \% ; p<.001)$, and gastroplasty $(68.2 \% ; p$ $<.001$ ), with patients who undergo Roux en Y gastric bypass consistently exhibiting greater weight loss than patients treated via other surgical methods (Buchwald et al., 2004; Maggard et al., 2005). Another recent meta-analysis ( $n=147$ studies) examined the efficacy of surgery versus other treatments. Maggard and colleagues (2005) concluded that bariatric surgery induces greater weight loss for severely obese individuals (BMI $\geq 40 \mathrm{~kg} / \mathrm{m}^{2}$ ) than traditional methods such as diet, exercise, and pharmacotherapy. In addition, the authors determined that weight loss among surgical patients $(20-40 \mathrm{~kg})$ was significantly higher than for those treated traditionally $(2-5 \mathrm{~kg})$ after one and two years. However, it is important to note that the patient population in medical weight loss treatments exhibits an average BMI of $33 \mathrm{~kg} / \mathrm{m}^{2}$, which is lower than the average for patients seeking weight loss surgery. Only one study has examined the use of bariatric surgery for patients with a BMI between 35 and $39 \mathrm{~kg} / \mathrm{m}^{2}(n=80)$, but results indicated that surgery may be more effective than medical treatment for this population as well (O'Brien et al., 2006). The authors examined changes in weight among participants who underwent adjustable laparoscopic gastric band surgery and participants assigned to a program including low-calorie diet, lifestyle change, and pharmacotherapy. At 24 months, participants receiving surgery exhibited greater weight loss, with a mean of $87.2 \%$ (CI, $77.7 \%$ to $96.6 \%$ ) of excess weight lost, while participants in the nonsurgical group had a mean loss of $21.8 \%$ (CI, $11.9 \%$ to $31.6 \%)$ of excess weight $(p<0.001)$. 
In addition to inducing increased weight loss, results of Maggard et al.'s (2005) metaanalysis indicated that bariatric surgery promotes greater sustained weight loss over time. While many studies examining the efficacy of medical treatments report significant weight regain after twelve months, research of bariatric procedures has supported sustained weight loss of up to ten years post-surgery. For a comparison of outcomes after behavioral treatment and surgical treatment, see Table 1. The Swedish Obese Subjects (SOS) study, a non-randomized intervention trial examining weight loss outcomes in more than 4,000 surgical and nonsurgical patients, found a higher mean weight change (16.1\% loss) among surgical patients than for controls $(1.6 \%$ increase) after ten years ( $p<.001$; Sjöström et al., 2004). However, additional research indicates that some patients fail to lose excess weight and others regain significant amounts of weight over time. For example, one study of patients at five and ten years post-surgery found a failure (defined as maintenance of a BMI $\geq 35 \mathrm{~kg} / \mathrm{m}^{2}$ for morbidly obese and BMI $\geq 40 \mathrm{~kg} / \mathrm{m}^{2}$ for super obese) rate of $20.4 \%$ for morbidly obese individuals and $34.9 \%$ for super obese individuals after ten years (Christou, Look, \& MacLean, 2006).

Despite the potential for weight regain, there are a number of positive physical and psychological outcomes that can occur following bariatric surgery. For instance, the recent metaanalysis of 136 studies found that the majority of bariatric patients experience improvement in or complete resolution of comorbid conditions such as diabetes mellitus, hyperlipidemia, hypertension, and obstructive sleep apnea (Buchwald et al., 2004). In one 14-year follow-up study, $82 \%$ of patients experienced complete elimination of diabetes following gastric bypass (Pories et al., 1995), and meta-analysis reported complete resolution in $76.8 \%$ of patients and improvements in $86 \%$ of patients (Buchwald et al.). Elimination of hypertension has been reported for one-half to two thirds of all bariatric patients, and hyperlipidemia improvements 
experienced by about 70\% (Buchwald et al.). Finally, dramatic changes are exhibited for patients with obstructive sleep apnea, with around $80 \%$ experiencing improvement or complete resolution.

Overall, the increased health benefits associated with bariatric surgery mean that many patients can expect a marked increase in life expectancy (Buchwald et al., 2004). Fortunately, along with increased quantity of life, bariatric patients are also likely to experience increased quality of life. A retrospective study of 200 patients found that quality of life was significantly improved for five years following surgery $(p=0.003)$. After five years weight regain was common and a decrease in quality of life exhibited; however, patients continued to maintain that quality of life remained higher than before surgery completion (Folope, et al., 2008).

Perceptions of quality of life are likely influenced by many psychosocial factors. Systematic review indicates that after bariatric surgery patients are more likely to experience improved social relationships, have increased educational opportunities, and report fewer symptoms of affective disorders and psychopathology (Herpertz et al., 2003; Shiri, Gurevich, Feintuch, \& Beglaibter, 2007); in addition, patients may also report increased physical functioning, decreased bodily pain, increased self-confidence, and improved body image (Buchwald et al., 2004; Vazzana, 2008). Within the Swedish Obese Subjects study (SOS), high average scores for both depression and anxiety were demonstrated at baseline for both control and surgical participants. After two and four years a dose-response relationship was indicated for negative mood, with those individuals losing greater amounts of weight reporting fewer symptoms of depression; scores on anxiety were nonsignificantly lower, and not associated with weight loss $(p<.01)$ (Karlsson, Sjöströem, \& Sullivan, 1998). 
Because patients improve in physical and psychological status, costs associated with health care services are likely to decrease. A study of the cost effectiveness of bariatric surgery noted that the amelioration of comorbidities like diabetes and hypertension were reflected in decreased use of prescription medications, physician visits, and hospital visits (Crémieux et al., 2009). The authors also determined that while the cost of surgery was between $\$ 17,000$ and $\$ 26,000$ on average, this cost was recouped within two to four years for most patients.

Considering the potential cost-effectiveness of bariatric surgery and the myriad positive benefits experienced by patients, it is no wonder that surgical methods for weight loss continue to grow in popularity. In fact, in the span of one year, from 2002 to 2003 , the number of bariatric surgeries performed in the U.S. rose from 63,000 operations to 98,000 operations (Karmali \& Shaffer, 2005). The evidence in favor of this form of treatment for obesity is so strong that the American Dietetics Association published a position paper in favor of bariatric surgery as the "most effective" approach for weight management for obese individuals; however, it was also suggested that comprehensive pre- and post-surgical behavioral therapy be implemented in order to maximize long-term outcomes (Rowe \& Davis, 2007).

Much consensus exists that for long-term weight loss maintenance to occur, lifestyle change is necessary. Unfortunately, while bariatric surgery may currently be the most effective form of treatment for severe obesity, approximately $20-30 \%$ of patients fail to lose significant amounts of weight or regain large amounts of weight within a few years after surgery (Sarwer et al., 2009). This suboptimal weight loss or weight loss maintenance likely occurs because of a lack of behavioral change, such as chronic sedentarism or a return to maladaptive eating patterns, and is not often due to surgical malfeasance. Therefore, further examination of the use of behavioral modification in the surgical treatment of obesity is warranted. 


\section{The Use and Efficacy of Behavior Modification and Bariatric Surgery in Combination}

Most bariatric surgical programs focus patient education on immediate outcomes such as risk and benefits of surgery and preoperative preparation for surgery (Rowe \& Davis, 2007). In addition, much emphasis has been placed on psychological screening of surgical candidates in order to ensure that patients have no psychiatric conditions that could interfere with successful surgical outcome. However, despite the identification of various factors that may influence results, such as socioeconomic status, pre-surgical BMI, and comorbidities, little consensus exists as to how well these constructs predict surgical outcome (Huberman, 2008). Thus, while preoperative evaluation by a multidisciplinary team is common, methods and criteria for screening vary significantly (Wadden \& Sarwer, 2006); in addition, many surgical centers employ their own mental health professionals to conduct these screenings, creating an inherent conflict of interest.

In 1991, a consensus panel sponsored by the National Institutes of Health (NIH) made recommendations for bariatric patient selection and preoperative management. The panel determined that patients should be motivated and well-informed, and have the opportunity to discuss potential outcome and compliance with professionals (Wadden \& Sarwer, 2006). Evaluating motivation or readiness for surgery is a concept that has been explored only recently, and while many believe that readiness is important to success, research found that readiness for surgery did not predict weight loss outcomes or compliance (Dixon et al., 2009).

It is interesting to note though, that the authors did not examine readiness to change lifestyle behaviors that affect weight status after surgery, including dietary modifications and physical activity. Another study by Chevallier et al. (2007) found willingness to change eating habits and physical activity patterns after surgery to be predictors of excess weight loss $(p<$ 
$.001)$; patients who did not increase physical activity post-surgery were 2.3 times more likely to experience weight loss failure, and patients who did not change their eating habits were 2.2 times more likely to be unsuccessful. Therefore, a trend in psychological preoperative assessment has been to identify potential risk factors for non-adherence to behavioral modification and strategize treatment plans in order to improve compliance with follow-up and lifestyle changes (Franks \& Kaiser, 2008).

Some bariatric providers require that patients exhibit the ability to comply with behavioral recommendations such as diet and increased physical activity prior to surgery; others require proof that traditional methods of weight loss have been attempted and proven ineffective by patients (Rowe \& Davis, 2007). However, some research indicates that bariatric patients may have a long history of failed weight loss attempts, including through self-directed dieting and participation in commercial weight loss programs, and necessitating further weight management endeavors before surgery may be unwarranted (Gibbons et al., 2006). Still, previous study and meta-analysis has shown weight loss prior to surgery was related to greater post-operative weight loss (Alvarado et al., 2005; Livhits et al., 2009); thus, there has been some recommendation for the incorporation of behavioral therapy prior to surgery in order to maximize adherence to lifestyle modifications (Collazo-Clavell, Clark, McAlpine, \& Jensen, 2006).

Currently, there have been no published randomized controlled studies comparing outcome after bariatric surgery when behavioral modification services have been provided in advance versus surgery alone. However, one study did examine patient satisfaction with a sixweek behavioral modification program (Brandenburg \& Kotlowski, 2005). The authors found that patients perceived such services as being helpful for making lifestyle changes (mean score 4.45 on a 5-point Likert scale), and were highly satisfied with the program overall (mean score 
4.51); patient satisfaction and perceived usefulness were not significantly related to weight loss though $(r=.05, p=.69 ; r=.05, p=.71)$. A limitation of this study was that patients were surveyed one year after surgery, and retrospective perceptions could be biased by the increased psychosocial functioning patients are likely to experience after surgery (i.e., they may be more likely to evaluate anything related to surgery positively as surgery is associated with improved quality of life).

Another study was completed comparing the provision of a behavioral modification program before surgery to a program provided after surgery (Leahy, Bond, Irwin, Crowther, \&Wing, 2008). Both were 10-week programs targeting maladaptive eating habits, and 21 patients were referred to the pre-surgical intervention and 11 were referred to the post-surgical intervention. Results showed that post-surgical patients were more likely to initiate treatment $\left(\chi^{2}\right.$ $(1)=10.06, p=.002$ ), and $100 \%$ of the post-surgical group attended the first session, while only $43 \%$ of the pre-surgical group attended the first program session. In addition, post-surgical patients attended a greater number of sessions overall $(t(18)=2.51, p=.02)$ and were more likely to complete the program than pre-surgical patients $\left(\chi^{2}(1)=7.21, p=.007\right) ; 91 \%$ of patients in the post-surgical group completed the intervention while $14 \%$ of patients in the presurgical group finished the intervention.

Leahy et al. (2008) asserted that patients may be more receptive to behavioral modification following surgery due to the struggles associated with changing health habits; when these difficulties are experienced patients may see greater value in supportive services and be more motivated to change their behavior in order to maximize outcomes. As well, pre-operative patients may have unrealistic expectations regarding the surgery itself; previous research found that patients overestimate the effects of surgery on eating behaviors and weight loss 
(Bauchowitz, Azarbad, Day, \& Gonder-Frederick, 2007). Maladaptive health behaviors are often ingrained over time and thus resistant to surgical intervention; therefore behavioral intervention in conjunction with surgical procedures can be an important component of multidisciplinary treatment programs both before and after surgery.

Within the bariatric field however, it is not common for surgical providers to include structured behavioral modification programs. Instead, recommendations for behavioral changes (such as dietary restrictions and physical activity guidelines) are made to patients following surgery and follow-up appointments with a medical professional are then scheduled in order to monitor possible surgical complications and compliance. The length of time between follow-up visits varies by provider, but generally patients may be asked to return at three months postsurgery, six-months post-surgery, one-year post-surgery, and then annually; many bariatric surgeons recommend that continuation of annual follow-up continue for the duration of the patient's lifespan (Harper, Madan, Ternovits, \& Tichansky, 2007).

An important finding from Dixon et al.'s (2009) previously discussed research into patient readiness for surgery was a correlation between attendance at follow-up appointments and weight loss $(r=+0.16, p=0.02)$, with those attending more visits experiencing increased weight loss. This is a common finding in the bariatric surgery literature; patients who attend follow-up visits are more likely to exhibit positive results. However, compliance with follow-up visits is low, and attrition rates vary from 10-45\% (Mathus-Vliegen, 2007).

Powers , Rosemurgy, Boyd, and Perez (1997) attempted to complete follow-up study with 131 bariatric patients a mean duration of 5.7 years post-surgery. One-third of these patients could not be evaluated at follow-up, despite "massive efforts" on the part of the researchers to establish contact. Powers et al. (1997) concluded that some patients did not want to be found or 
participate in follow-up, but made no attempts at explaining why this may have been so. Reasons for non-compliance with follow-up visits may vary; however, one hypothesis for why patients do not return for further appointments with bariatric personnel is that they have experienced smaller weight losses than anticipated and are thus embarrassed or ashamed of a perceived lack of success. Appraising surgery to have been a failure, patients may then not be satisfied with surgical staff, leading to a lack of compliance. Conversely, patients may be highly satisfied with results after surgery and not perceive a need to return for follow-up. Lastly, patients may simply forget about scheduled visits, particularly if they are scheduled a year in advance (Harper et al, 2007).

Whatever the reason for noncompliance with follow-up appointments, it is clear that high rates of noncompliance occur and that less contact with professional staff following surgery can limit potential weight loss results. In one study, results showed that only $40 \%$ of patients returned for annual visits, and those individuals lost significantly less weight than patients who attended all scheduled follow-ups (Gould, Beverstein, Reinbardt, \& Garren, 2007). Wolfe, Kortner, and Kuhlmann (2001) reported that $90 \%$ of patients operated on in their hospital from 1990-1999 returned for the first meeting post-surgery; one year later only $27 \%$ of patients returned for follow-up.

Harper et al. (2007) examined differences in weight status among patients who returned for follow-up as scheduled versus patients who were prompted to return; of 105 consecutive patients, 48 did not return automatically for their follow-up visit. After analyzing differences between those who attended appointments without prompting and those were contacted to return, the authors found that more patients who attended follow-up on their own experienced weight loss success $(88 \%$, versus $67 \%$ for those who were reminded to return; $p<.002)$. As well, 
patients who returned to their visits without reminder lost greater amounts of excess body weight $(76 \%)$ than those who were contacted $(65 \% ; p<.003)$.

Harper et al. (2007) hypothesized that weight loss differences between the two groups may have been due to several things. One, patients who were compliant with follow-up appointments may have received increased education and support for lifestyle changes from staff, which could impact motivation and adherence. Previous study by Shen et al. (2004) found no discernable difference in saline volume among patients who attended follow-up after laparoscopic adjustable gastric banding and those who did not; however, excess weight loss was higher for patients who were compliant with follow-up appointments. Thus, if the adjustment of the band did not significantly differ between the two groups of patients, other factors like emotional support, motivation, and counseling could have impacted weight loss.

Harper et al.'s (2007) second hypothesis regarding differences in weight loss was that patients who were noncompliant with follow-up visits may also have been noncompliant with modifications to lifestyle behaviors such as diet and physical activity, which could limit weight loss outcomes. Little is known about the rates of compliance with recommendations for behavioral lifestyle modifications, but non-adherence to changes in eating behaviors and lack of regular physical activity have been associated with weight regain over time (Elkins et al., 2005; Hsu, Sullivan, \& Bennotti, 1997; Shah, Simha, \& Garg, 2006).

One study has examined patient compliance with behavioral modification recommendations. Elkins et al. (2005) followed 100 bariatric patients over the span of a year, and analyzed compliance with changes in eating behaviors and physical activity patterns at six months and twelve months through chart reviews. The highest levels of noncompliance were exhibited in snacking (37\% were noncompliant at twelve months) and exercise ( $41 \%$ were 
noncompliant at twelve months). It is interesting to note that patients in this study completed a six-month dietary counseling program prior to surgery; previously mentioned research has suggested that services provided preoperatively may not be as effective as those included postsurgery. Therefore, patients may benefit more from services proffered after surgery in order to help them adhere to recommendations related to diet and exercise. Elkins et al. (2005) supported this assertion, noting that while surgery can be considered "forced behavior modification," patients' ability to voluntarily adhere to behavioral changes over time may be of greater importance and require increased consideration and support.

Thus, inclusion of structured behavioral modification programs following bariatric surgery, rather than recommendations alone, may further contribute to enhanced weight loss and outcomes for patients. Following chart review analysis among 67 postoperative patients, Toussi, Fujioka, and Coleman (2009) found that 51\% were noncompliant with guidelines for exercise and $57 \%$ were not compliant with weight loss instructions; in addition, poor food choices increased significantly after surgery $\left(\chi^{2}(1)=25.00, p<0.001\right)$. Because of the difficulty in adhering to recommendations exhibited by patients, the authors recommended that bariatric staff increase the frequency of contact with patients, as well as require adherence to behavioral changes. One way to improve the likelihood that patients will adhere to such changes, and to increase practitioner contact, is to provide programs or educational support groups that target lifestyle modification.

While annual follow-up is typically completed by bariatric surgeons in order to assess for medical complications, lifestyle modification services can be implemented by mental health professionals or other trained specialists. Multidisciplinary teams are recommended for comprehensive bariatric treatment of obesity, and may include psychologists, psychiatrists, 
registered dietitians, exercise physiologists, and others (McMahon et al., 2006). Cognitive behavioral therapists may be especially competent to develop interventions that help improve weight loss and weight loss maintenance via sustained lifestyle changes to diet and physical activity (Kalarchian \& Marcus, 2003).

While it is clear that behavioral modification alone has limited efficacy in obesity treatment, when combined with other modalities like bariatric surgery it may serve to enhance and sustain successful weight loss. Klem et al. (2000) analyzed both bariatric patients and control patients from the National Weight Control Registry who had successfully lost and maintained significant weight loss, and found that bariatric patients reported lower levels of physical activity and higher fat intake; these results indicate that while surgical methods may promote increased weight loss in the short-term, they do not treat or change maladaptive habits that impact longterm health outcomes. One randomized controlled study has been completed that evaluated effects of a behavioral program on outcome after bariatric surgery (Tucker, Samo, Rand, \& Woodward, 1990). While the researchers did not find weight loss to be greater among the group that received the behavioral intervention, psychosocial functioning was higher and treatment participants reported increased physical activity and decreased fat intake; this is significant, as these are exactly the lifestyle changes that bariatric patients do not appear to be making on their own, and are health behaviors that will likely aid patients in maintaining success longer. Small sample size was a limitation of this study $(n=32)$, as was the intensity of the intervention; participants received only monthly consultations for a duration of six months, which may not have been adequate enough to facilitate enhanced weight loss outcomes.

More recently, researchers examined the effects of a lifestyle intervention on weight loss and maintenance as well as dietary and physical activity habits among female participants who 
underwent vertical banded gastroplasty $(n=30)$ and were randomly placed into either the intervention group or usual care group (Papalazarou et al., 2009). In this study, participants in the intervention group attended lifestyle sessions in addition to their regular bariatric follow-up for three years post-surgery (a total of 30 sessions). The researchers found significantly lower body weight among participants in the lifestyle group at one year $(84.4 \pm 3.9 \mathrm{~kg}$ vs. $98.4 \pm 4.4 \mathrm{~kg}, P<$ $0.05)$, two years $(83.0 \pm 3.3$ vs. $101.9 \pm 5.3 \mathrm{~kg}, p<0.001)$, and three years $(84.2 \pm 3.3$ vs. $102.5 \pm$ $3.5 \mathrm{~kg}, p<0.001$ ) post-surgery, as well as statistically higher percent excess weight loss. Significant differences were found related to dietary intake, with participants in the lifestyle intervention reporting an increased trend of fruit and vegetable consumption $(p<.05)$ at all three data points. Repeated measures ANOVA also showed significant differences in physical activity level overall and at 3 years in favor of the lifestyle group $(p<.001)$. The researchers noted that weight losses were comparable between the two groups during the first 9 months, during which time the effects of the surgical procedure limit nutritional intake; however, over time surgical patients are able to consume a broader spectrum of foods, and thus participation in the lifestyle intervention may have facilitated patients' making healthier choices and thus prolonging weight loss and weight loss maintenance.

In conclusion, it is clear that long-term weight loss success depends largely on lifestyle factors. Cook and Edwards (1999) identified key habits reported by gastric bypass patients who had maintained significant long-term excess weight loss, including eating well-balanced meals, drinking water, and exercising regularly. Behavioral modification programs utilized in conjunction with weight loss surgery provide opportunity for patients to develop and maintain effective habits such as those identified by Cook and Edwards (1999), as well as receive support 
for new healthy behaviors. Thus, future research analyzing the use and effectiveness of behavioral lifestyle modification with bariatric surgery is well warranted.

\section{Summary and Critique of the Literature}

In summary, it is clear that behavioral or lifestyle interventions for the treatment of obesity produce moderate short-term weight losses that can be beneficial for improved health and well-being. Unfortunately, long-term weight loss maintenance continues to be an issue, as more than $50 \%$ of patients in lifestyle modification programs are likely to return to baseline weight within five years of treatment (Perri \& Corsica, 2002). It is partially because of this lack of long-term efficacy through traditional methods that alternative treatments for obesity have become popular, including bariatric surgery; however, the potential benefit of behavioral treatment, with or without surgery, should not be overlooked.

Obesity is increasingly being acknowledged as a chronic disease, similar to diabetes or hypertension, that requires long-term care (Perri \& Corsica, 2002). As such, research is needed that examines the effects of behavioral treatments lasting longer than the current average of 1626 weeks. Enhanced patient-provider contact may allow patients to better integrate new behavioral changes into an overall lifestyle, thus improving weight loss maintenance. Prochaska and Velicer (1997) determined that creating new habits takes an average of six months, and thus extension of direct services to patients in behavioral programs should be extended to a minimum of six months to one year.

Even if extended treatment duration in behavioral programs improves weight loss maintenance, bariatric surgery will likely continue to be regarded as the most effective form of treatment for individuals with morbid obesity due to its impact on weight loss and comorbidities like diabetes. Research shows that individuals who are treated surgically lose more weight in 
both the short- and long-term, and many experience partial or complete resolution of related health problems including hypertension and sleep apnea (Buchwald et al., 2004; Maggard et al., 2005). Considering that rates of morbid obesity have quadrupled in the last 15 years (Ogden et al., 2006), it seems safe to assume that the use of surgical treatment will only increase over time; in fact, current research indicates procedures may be expanded to include individuals below the BMI threshold for morbid obesity (O’Brien et al., 2006).

Therefore, since surgical weight loss procedures are likely to only gain in popularity, research is needed to determine what role behavioral modification programs can play in aiding weight loss and weight loss maintenance for surgical patients. Some estimates have indicated that $20-30 \%$ of patients fail to lose significant amounts of weight or regain large amounts of weight within a few years after surgery (Sarwer et al., 2009); one explanation for why this is so is a lack of change to diet or physical activity behaviors. One study examined patients' $(n=909)$ explanations for weight regain, and found that the most frequently cited were non-specified reasons related to diet (25.3\%), physical activity (21.0\%), and lack of motivation/selfcontrol/will power (19.7\%) (Hwang et al., 2009). The authors recommended that bariatric programs incorporate specialized weight loss counselors that can address these topics both before and after surgery, perhaps through some type of behavioral modification program.

To date, only four studies were identified that examined the use of behavioral modification either before or after surgery (Brandenburg \& Kotlowski, 2005; Leahy et al., 2008; Papalazarou et al., 2009; Tucker et al., 1990). In addition, due to the lack of specificity in accreditation standards for bariatric facilities, it is unclear how many bariatric facilities offer some type of behavioral modification program to patients and what behavioral services entail. Thus, future research is needed to determine what kind of services are being offered to patients 
currently and how effective these services are for helping patients make the lifestyle changes necessary to enhance and maintain weight losses.

Some research has been done examining patients' knowledge of the surgical process and perceptions of readiness to manage post-operative changes that indicates current services may be lacking. Marchand et al. (2007) completed phenomenological interviews with 30 obese participants who were preparing to undergo bariatric surgery. All patients had been under the care of a medical professional for at least one year and during that time had attended medical, psychological, and dietary consultations as well as group therapy. The authors found that onethird of the participants expressed erroneous knowledge related to the surgical process and dietary changes (e.g. "It is possible to eat almost everything normally"). In addition, less than half of the participants expressed anything related to long-term care, which may indicate that bariatric patients have faulty expectations about what will be required of them to maintain health behavior changes.

Another study surveyed patients $(n=550)$ who had undergone bariatric surgery to determine their perceptions of pre-operative education and information related to a common side effect of some procedures known as "dumping syndrome" (Heinlein, 2009). The author found that many participants reported experiencing symptoms that were not covered in pre-surgical education; in addition, several participants reported not receiving any information on dumping syndrome before surgery. These results highlight the need for improved and standardized care in the bariatric field; patients may not currently be receiving services that adequately prepare them for the changes they will experience with a life-altering surgical procedure.

As can be seen from the review of literature, while much research has been done on behavioral modification for obesity in general, little is known about how it can be used with 
newer treatments such as bariatric surgery. The following study will attempt to analyze the role behavioral services currently play in bariatric procedures and will survey patients' perceptions of and satisfaction with services received. Hopefully, increased knowledge in these areas will help practitioners to enhance or add services, such that patient weight loss outcomes can be maximized and long-term lifestyle change may be achieved. 


\section{References}

American College of Sports Medicine. (ACSM; 2000). Guidelines for exercise testing and prescription ( $6^{\text {th }}$ edition). Baltimore, MD: Lippincott.

Alvarado, R., Alami, R. S., Hsu, G., Safadi, B. Y., Sanchez, B. R., Morton, J. M., \& Curet, J. M. (2005). The impact of preoperative weight loss in patients undergoing laparoscopic Roux-en-Y gastric bypass. Obesity Surgery, 15, 1282-1286.

Andersen, R. E., Wadden, T. A., Bartlett, S. J., Zemel, B., Verde, T. J., \& Franckowiak, S. C. (1999). Effects of lifestyle activity vs. structured aerobic exercise in obese women: A randomized trial. Journal of the American Medical Association, 281, 335-40.

Bachman, K. H. (2007). Obesity, weight management, and health care costs: A primer. Disease Management, 10, 129-137.

Baker, R. C. \& Kirschenbaum, D. S. (1998). Weight control during the holidays: Highly consistent self-monitoring as a potentially useful coping mechanism. Health Psychology, $17,367-70$.

Bauchowitz, A., Azarbad, L., Day, K., \& Gonder-Frederick, L. (2007). Evaluation of expectations and knowledge in bariatric surgery patients. Surgery for Obesity and Related Diseases, 3, 554-558.

Black, D. R., Gleser, L. J., \& Kooyers, K. J. (1990). A meta-analytic evaluation of couples weight-loss programs. Health Psychology, 9, 330-47.

Booth, F.W.,\& Chakravarthy, M.V. (March, 2002) Cost and consequences of sedentary living: New battleground for an old enemy. President's Council on Physical Fitness and Sports Research Digest, 1-8. 
Blaine, B. E., Rodman, J., \& Newman, J. M. (2007). Weight loss treatment and psychological well-being: A review and meta-analysis. Journal of Health Psychology, 12, 66-82.

Bray, G. A. (2001). Drug treatment of obesity. Reviews in Endocrine and Metabolic Disorders, 2, 403-418.

Brandenburg, D. \& Kotlowski, R. (2005). Practice makes perfect? Patient response to a prebariatric surgery behavior modification program. Obesity Surgery, 15, 125-132.

Brownell, K. D. \& Horgen, K. B. (2003). Food fight: The inside story of America's obesity crisis and what we can do about it. Chicago, IL: Contemporary Books.

Buchwald, H., Avidor, Y., Braunwald, E., Jensen, M. D., Pories, W., Fahrbach, K., \& Schoelles, K. (2004). Bariatric surgery: A systematic review and meta-analysis. Journal of the American Medical Association, 292, 1724-1737.

Butryn, M. L., Phelan, S., Hill, J. O., \& Wing, R. R. (2007). Consistent self-monitoring of weight: A key component of successful weight loss maintenance. Obesity, 15, 30913096.

Carels, R. A., Darby, L. A., Rydin, S., Douglass, O. M., Cacciapaglia, H. M., \& O’Brien, W. H. (2005). The relationship between self-monitoring, outcome expectancies, difficulties with eating and exercise, and physical activity and weight loss treatment outcomes. Annals of Behavioral Medicine, 30, 182-90.

Cerulli, J. \& Malone, M. (1998). Outcomes of pharmacological and surgical treatment for obesity. Pharmacoeconomics, 14, 269-283.

Chevallier, J., Paita, M., Rodde-Dunet, M., Marty, M., Nogues, F., Slim, K., \& Basdevant, A. (2007). Predictive factors of outcome after gastric banding: A nationwide survey on the role of center activity and patients' behavior. Annals of Surgery, 246, 1034-1039. 
Christou, N. V., Look, D., \& MacLean, L. D. (2006). Weight gain after short- and long- limb gastric bypass in patients followed for longer than 10 years. Annals of Surgery, 244, 734740.

Christou, N. V., Sampalis, J. S., Liberman, M., Look, D., Auger, S., McLean, A. P., \& MacLean, L. D. (2004). Surgery decreases long-term mortality, morbidity, and health care use in morbidly obese patients. Annals of Surgery, 240, 416-424.

Collazo-Clavell, M. L., Clark, M. M., McAlpine, D. E., \& Jensen, M. D. (2006). Assessment and preparation of patients for bariatric surgery. Mayo Clinic Proceedings, 81, S11-S17.

Cook, C. M. \& Edwards, C. E. (1999). Success habits of long-term gastric bypass patients. Obesity Surgery, 9, 80-82.

Crémieux, P., Buchwald, H., Shikora, S. A., Ghosh, A., Yang, H. E., \& Buessing, M. (2008). A study on the economic impact of bariatric surgery. American Journal of Managed Care, $14,589-596$.

Dixon, J. B., Laurie, C. P., Anderson, M. L., Hayden, M. J., Dixon, M. E., \& O’Brien, P. E. (2009). Motivation, readiness to change, and weight loss following adjustable gastric band surgery. Obesity, 17, 698-705.

Douketis, J. D., Macie, C., Thabane, L., \& Williamson, D. F. (2005). Systematic review of longterm weight loss studies in obese adults: Clinical significance and applicability to clinical practice. International Journal of Obesity, 29, 1153-1167.

Eckel, R. H. (2008). Nonsurgical management of obesity in adults. The New England Journal of Medicine, 358, 1941-50.

Elder, K. A. \& Wolfe, B. M. (2007). Bariatric surgery: A review of procedures and outcomes. Gastroenterology, 132, 2253-2271. 
Elkins, G., Whitfield, P., Marcus, J., Symmonds, R., Rodriguez, J., \& Cook, T. (2005). Noncompliance with behavioral recommendations following bariatric surgery. Obesity Surgery, 15, 546-551.

Folope, V., Hellot, M. F., Kuhn, J. M., Ténière, P. Scotté, M., \& Déchelotte, P. (2008).Weight loss and quality of life after bariatric surgery: A study of 200 patients after vertical gastroplasty or adjustable gastric banding. European Journal of Clinical Nutrition, 62, $1022-1030$.

Foreyt, J. P., \& Goodrick, K. (1993). Evidence for success of behavior modification in weight loss and control. Annals of Internal Medicine, 119, 698-701.

Foreyt, J. P. \& Poston, W. S. C. (1998). The role of the behavioral counselor in obesity treatment. Journal of the American Diabetic Association, 98, S27-S30.

Foster, G. D., Wadden, T. A., Vogt, R. A., \& Brewer, G. (1997). What is a reasonable weight loss? Patients' expectations and evaluations of obesity treatment outcomes. Journal of Consulting and Clinical Psychology, 65, 79-85.

Franks, S. F. \& Kaiser, K. A. (2008). Predictive factors in bariatric surgery outcomes: What is the role of the preoperative psychological evaluation? Primary Psychiatry, 15, 74-83.

Galani, C. \& Schneider, H. (2007). Prevention and treatment of obesity with lifestyle interventions: Review and meta-analysis. International Journal of Public Health , 52, $348-359$.

Gibbons, L. M., Sarwer, D. B., Crerand, C. E., Fabricatore, A. N., Kuehnel, R. H., Lipschutz, P. E., et al. (2006). Previous weight loss experiences of bariatric surgery candidates: How much have patients dieted prior to surgery? Obesity, 14, 70S-76S. 
Gould, J. C., Beverstein, G., Reinbardt, S., \& Garren, M. J. (2007). Impact of routine and longterm follow-up on weight loss after laparoscopic gastric bypass. Surgery for Obesity and Related Diseases, 3, 627-630.

Hainer, V., Toplak, H., \& Mitrakou, A. (2008). Treatment modalities of obesity. Diabetes Care, 31, S269-S277.

Hamilton, M. \& Greenway, F. (2004). Evaluating commercial weight loss programmes: An evolution in outcomes research. Obesity Reviews, 5, 217-232.

Harper, J., Madan, A. K., Ternovits, C. A., \& Tichansky, D. S. (2007). What happens to patients who do not follow-up after bariatric surgery? The American Surgeon, 73, 181-184.

Harvey-Berino, J., Pintauro, S. J., \& Gold, E. C. (2002). The feasibility of using Internet support for the maintenance of weight loss. Behavioral Modification, 26, 103-16.

Haskell, W. L., Lee, I., Pate, R. R., Powell, K. E., Blair, S. N., Franklin, B. A., et al. (2007). Physical activity and public health: Updated recommendation for adults from the American College of Sports Medicine and the American Heart Association. Medicine \& Science in Sports \& Exercise, 39, 1423-1434.

Heinlein, C. R. (2009). Dumping syndrome in Roux-en-Y bariatric surgery patients: Are they prepared? Bariatric Nursing and Surgical Patient Care, 4, 39-47.

Herpertz, S., Kielmann, R., Wolf, A. M., Langkafel, M., Senf, W., \& Hebebrand, J. (2003). Does obesity surgery improve psychosocial functioning? A systematic review. International Journal of Obesity, 27, 1300-1314.

Hsu, L. K., Sullivan, S. P., \& Benotti, P. N. (1997). Eating disturbances and outcome of gastric bypass surgery: A pilot study. International Journal of Eating Disorders, 21, 385-390. 
Huberman, W. L. (2008). One psychologist's 7-Year experience in working with surgical weight loss: The role of the mental health professional. Primary Psychiatry, 15, 42-47.

Hwang, K. O., Childs, J. H., Goodrick, G. K., Aboughali, W. A., Thomas, E. J., Johnson, C. W., et al. (2009). Explanations for unsuccessful weight loss among bariatric surgery candidates. Obesity Surgery, 19, 1377-1383.

Jakicic, J. M., Winters, C., Lang, W., \& Wing, R. R. (1999). Effects of intermittent exercise and use of home exercise equipment on adherence, weight loss, and fitness in overweight women: A randomized trial. Journal of the American Medical Association, 282, 1554-60.

Jeffery, R. W. \&Wing, R. R. (1995). Long-term effects of interventions for weight loss using food provision and monetary incentives. Journal of Consulting and Clinical Psychology, 63, 793-796.

Jones, F., Harris, P., Waller, H., \& Coggins, A. (2005). Adherence to an exercise prescription scheme: The role of expectations, self-efficacy, stage of change and psychological wellbeing. British Journal of Health Psychology, 10, 359-378.

Jones, L. R., Wilson, C. I., \& Wadden, T. A. (2007). Lifestyle modification in the treatment of obesity: An educational challenge and opportunity. Clinical Pharmacology \& Therapeutics, 81, 776-779.

Joyal, S. V. (2004). A perspective on the current strategies for the treatment of obesity. Central Nervous System \& Neurological Disorders, 3, 341-356.

Kalarchian, M. A. \& Marcus, M. D. (2003). Management of the bariatric surgery patient: Is there a role for the cognitive behavior therapist? Cognitive and Behavioral Practice, 10, 112119. 
Karlsson, J., Sjostrom, L., \& Sullivan, M. (1998). Swedish obese subjects (SOS) - an intervention study of obesity. Two-year follow-up of health-related quality of life (HRQL) and eating behavior after gastric surgery for severe obesity. International Journal of Obesity Related Metabolic Disorders, 22, 113-126.

Karmali, S. \& Shaffer, E. (2005). The battle against the obesity epidemic: Is bariatric surgery the perfect weapon? Clinical \& Investigative Medicine, 28, 147-156.

Kimiciek, J. (2002). The intrinsic exerciser: Discovering the joy of exercise. New York: Houghton Mifflin.

Klem, M. L., Wing, R. R., Chang, C. H., Lang, W., McGuire M. T., Sugerman, H. J., et al. (2000). A case-control study of successful maintenance of a substantial weight loss: Individuals who lost weight through surgery versus those who lost weight through nonsurgical means. International Journal of Obesity, 24, 573-579.

Klem, M. L., Wing, R. R., McGuire, M. T., Seagle, H. M., \& Hill, J. O. (1997). A descriptive study of individuals successful at long-term maintenance of substantial weight loss. American Journal of Clinical Nutrition, 66, 239-46.

Kushner, R. (2005). Diets, drugs, exercise, and behavioral modification: Where these work and where they do not. Surgery for Obesity and Related Diseases, 1, 120-122.

Leahy, T. M., Bond, D. S., Irwin, S. R., Crowther, J. H., \& Wing, R. R. (2008). When is the best time to deliver behavioral intervention to bariatric surgery patients: Before or after surgery? Surgery for Obesity and Related Diseases, 5, 99-103.

Lemmens, V., Oenema, A., Klepp, K. I., Henricksen, H. B., \& Brug, J. (2008). A systematic review of the evidence regarding efficacy of obesity prevention interventions among adults. Obesity Reviews, 9, 446-455. 
Levy, R. L., Finch, E. A., Crowell, M. D., Talley, N. J., \& Jeffery, R. W. (2007). Behavioral intervention for the treatment of obesity: Strategies and effectiveness data. American Journal of Gastroenterology, 102, 2314-2321.

Livhits, M., Mercado, C., Yermilov, I., Parikh, J. A., Dutson, E., Mehran, A., et al. (2009). Does weight loss immediately before surgery improve outcomes: A systematic review. Surgery for Obesity and Related Diseases, 5, 713-721.

Lombard, D. N., Lombard, T. N., \& Winett, R. A. (1995). Walking to meet health guidelines: The effect of prompting frequency and prompt structure. Health Psychology, 14, 164170.

Lox, C., Martin Ginis, K., \& Petruzzello, S. J. (2006). The psychology of exercise: Integrating theory and practice. Scottsdale, AZ: Holcombe Hathaway Publishers.

Maggard, M. A., Shugarman, L. R., Suttorp, M., Maglione, M., Sugarman, H. J., Livingston, E. H., et al. (2005). Meta-analysis: Surgical treatment of obesity. Annals of Internal Medicine, 142, 547-559.

Marchand, C., Poitou, C., Pinosa, C., Dehaye, B., Basdevant, A., \& d'Ivernoise, J. (2007). Cognitive structures of obese patients undergoing bariatric surgery: A concept mapping analysis. Obesity Surgery, 17, 1350-1356.

Marcus, J. D. \&Elkins, G. R. (2004). Development of a model for a structured support group for patients following bariatric surgery. Obesity Surgery, 14, 103-106.

Mathus-Vliegen, E. M. S. (2009). Long-term health and psychosocial outcomes from surgically induced weight loss: results obtained in patients not attending protocolled follow-up visits. International Journal of Obesity, 31, 299-307. 
McMahon, M. M., Sarr, M. G., Clark, M. M., Gall, M. M., Knoetgen, J., Service, J., et al. (2006). Clinical management after bariatric surgery: Value of a multidisciplinary approach. Mayo Clinic Proceedings, 81, S34-S45.

Melin, I., Karlström, B., Lappalainen, R., Berglund, L., Mohsen, R., \& Vessby, B. (2003). A programme of behaviour modification and nutrition counselling in the treatment of obesity: A randomized 2-y clinical trial. International Journal of Obesity, 27, 1127-1135.

Mokdad, A. H., Ford, E. S., Bowman, B. A., Dietz, W. H., Vinicor, F., Bales, V. S., et al. (2003). Prevalence of obesity, diabetes, and obesity-related health risk factors, 2001. Journal of the American Medical Association, 289, 76-79.

Nir, Z., \& Neumann, L. (1995). Relationship among self-esteem, internal-external locus of control, and weight change after participation in a weight reduction program. Journal of Clinical Psychology, 51, 482-490.

O’Brien, P. E., Dixon, J. B., Laurie, C., Skinner, S., Proietto, J., McNeill, J., et al. (2006). Treatment of mild to moderate obesity with laparoscopic adjustable gastric banding or an intensive medical program. Annals of Interntal Medicine, 144, 625- 633.

Ogden, C. L., Carroll, M. D., Curtin, L. R., McDowell, M. A., Tabak, C. J., \& Flegal, K. M. (2006). Prevalence in overweight and obesity in the United States, 1999-2004. Journal of the American Medical Association, 295, 1549-1555.

Orchard, T. J., Temprosa, M., Goldberg, R., Haffner, S., Ratner, R., Marcovina, S., et al. (2005). The effect of metformin and intensive lifestyle intervention on the metabolic syndrome: The diabetes prevention program randomized trial. Annals of Internal Medicine, 142, 611-619.

Papalazarou, A., Yannakoulia, M., Kavouras, S. A., Komesidou, V., Dimitriadis, G., 
Papakonstantinou, A., et al. (2009). Lifestyle intervention favorably affects weight loss and maintenance following obesity surgery. Obesity, 18, 1348-1353.

Perri, M. G., \& Corsica, J. A. (2002). Improving the maintenance of weight lost in behavioral treatment of obesity. In T. A. Wadden \& A. J. Stunkard (Eds.), Handbook of obesity treatment, (pp. 357-379). New York, NY: Guilford Press.

Perri, M. G., Nezu, A. M., McKelvey, W. F., Shermer, R. L., Renjilian, D. A., \& Viegener, B. J. (2001). Relapse prevention training and problem-solving therapy in the long-term management of obesity. Journal of Consulting and Clinical Psychology. 69, 722-726.

Perri, M.G., Shapiro, R.M., Ludwig, W.W., Twentyman, C.T. \& McAdoo, W.G. (1984). Maintenance strategies for the treatment of obesity: An evaluation of relapse prevention training and posttreatment contact by mail and telephone. Journal of Consulting and Clinical Psychology, 52, 404-413.

Polivy, J. \& Herman, C. P. (2002). If at first you don't succeed: False hopes of selfchange. American Psychologist, 57, 677-689.

Pories, W. J., Swanson, M. S., MacDonald, K. G., Long, S. B., Morris, P. G., Brown, B. M., et al. Who would have thought it? An operation proves to be the most effective therapy for adult-onset diabetes mellitus. Annals of Surgery, 222, 339-50.

Powers, P. S., Rosemurgy, A., Boyd, F., \& Perez, A. (1997). Outcome of gastric restriction procedures: Weight, psychiatric diagnoses, and satisfaction. Obesity Surgery, 7, 471-477.

Prochaska, J. O. \& Velicer, W. F. (1997). The transtheoretical model of health behavior change. American Journal of Health Promotion, 12, 38-48.

Renjilian, D. A., Perri, M. G., Nezu, A. M., McKelvey, W. F., Shermer, R. L. \& 
Anton, S. D. (2001). Individual versus group therapy for obesity: Effects of matching participants to their treatment preferences. Journal of Consulting and Clinical Psychology, 69, 717-721.

Rowe, B. \& Davis, L. (2007). Bridging the divide between bariatric surgery and traditional weight loss programs. Bariatric Nursing and Surgical Patient Care, 2, 109-112.

Sarwer, D. B., von Sydow Green, A., Vetter, M. L., \& Wadden, T. A. (2009). Behavior therapy for obesity: Where are we now? Current Opinion in Endocrinology, Diabetes, \& Obesity, $16,347-352$.

Sarwer, D. B. \& Wadden, T. A. (1999). The treatment of obesity: What's new, what's recommended. Journal of Women's Health \& Gender-Based Medicine, 8, 483-493.

Shah, M., Simha, V., \& Garg, A. (2006). Review: Long-term impact of bariatric surgery on body weight, comorbidities, and nutritional status. The Journal of Clinical Endocrinology \& Metabolism , 91, 4223-4231.

Shen, R., Dugay, G., Rajaram, K., Cabrera, I., Siegel, N., \& Ren, C. J. (2004). Impact of patient follow-up on weight loss after bariatric surgery. Obesity Surgery, 14, 514- 519.

Shiri, S., Gurevich, T., Feintuch, U., \& Beglaibter, N. (2007). Positive psychological impact of bariatric surgery. Obesity Surgery, 17, 663-668.

Sjöström, L., Lindroos, A. K., Peltonen, M., Torgerson, J., Bouchard, C., Carlsson, B.,et al. (2004). Lifestyle, diabetes, and cardiovascular risk factors 10 years after bariatric surgery. New England Journal of Medicine, 351, 2683-2693.

Song, Z., Reinhardt, K., Buzdon, M., \& Liao, P. (2008). Association between support group attendance and weight loss after Roux-en-Y gastric bypass. Surgery for Obesity and Related Diseases, 4, 100-103. 
Smith, B. L. (2005). Bariatric surgery: It's no easy fix. $R N$, 68, 58-63.

Smith, C. F. \& Wing, R. R. (2000). New directions in behavioral weight-loss programs. Diabetes Spectrum, 13, 142-155.

Tate, D. F., Wing, R. R., \& Winett, R. A. (2001). Using Internet technology to deliver a behavioral weight loss program. Journal of the American Medical Association, 285, 1172-7.

Tucker, J. A., Samo, J. A., Rand, C. S., \& Woodward, E. R. (1990). Behavioral interventions to promote adaptive eating behavior and lifestyle changes following surgery for obesity: Results of a two-year outcome evaluation. International Journal of Eating Disorders, 10, 689-698.

Vazzana, A. (2008). Psychological outcomes of bariatric surgery in morbidly obese adolescents. Primary Psychiatry, 15, 68-73.

Volek, J. S., Van Heest, J. L., \& Forsythe, C. E. (2005). Diet and exercise for weight loss: A review of current issues. Sports Medicine, 35, 1-9.

Wadden, T. A., Butryn, M. L., \& Byrne, K. J. (2004). Efficacy of lifestyle modification for longterm weight control. Obesity Research, 12, 151S-162S.

Wadden, T. A. \& Sarwer, D. B. (2006). Behavioral assessment of candidates for bariatric surgery: A patient-oriented approach. Obesity, 14, 53S-62S.

Wolfe, A. M., Kortner, B., \& Kuhlmann, H. W. (2001). Results of bariatric surgery. International Journal of Obesity, 25, S113-S114.

World Health Organization. (1998) Obesity: Preventing and managing the global epidemic. (World Health Organization, Geneva, Switzerland). 


\begin{tabular}{|c|c|c|c|c|c|c|c|c|c|c|c|}
\hline & $\begin{array}{l}\text { \# of } \\
\text { studies } \\
\text { included }\end{array}$ & $\begin{array}{l}\text { Average } \\
\text { sample size }\end{array}$ & $\begin{array}{l}\text { Average } \\
\text { length of } \\
\text { treatment }\end{array}$ & $\begin{array}{l}\text { Average } \\
\text { short-term } \\
\text { Weight loss } \\
(\mathrm{kg})\end{array}$ & $\begin{array}{l}\text { Short-term } \\
\text { effect of weight } \\
\text { loss treatment } \\
\text { on weight loss } \\
\text { (weighted } r \text { ) }\end{array}$ & $\begin{array}{l}\text { Average } \\
\text { length of } \\
\text { follow-up }\end{array}$ & $\begin{array}{l}\text { Average } \\
\text { weight loss } \\
\text { at follow- } \\
\text { up (kg) }\end{array}$ & $\begin{array}{l}\text { Long-term effect } \\
\text { of weight loss } \\
\text { treatment on } \\
\text { weight } \\
\text { (weighted } r \text { ) }\end{array}$ & Attrition & $\begin{array}{l}\text { Average } \\
\text { change in } \\
\text { fasting } \\
\text { glucose } \\
(\mathrm{mmol} / \mathrm{L})\end{array}$ & $\begin{array}{l}\text { Long-term } \\
\text { effects of } \\
\text { weight loss } \\
\text { treatment on } \\
\text { depression } \\
\text { (weighted } r \text { ) }\end{array}$ \\
\hline \multicolumn{12}{|l|}{$\begin{array}{l}\text { Behavioral } \\
\text { Treatment }\end{array}$} \\
\hline $\begin{array}{l}\text { Galani \& } \\
\text { Schneider, } \\
2007\end{array}$ & 17 & 471.4 & & & & 3.0 years & 3.49 & & 16.6 & -.15 & \\
\hline $\begin{array}{l}\text { Wadden, } \\
\text { Butryn, \& } \\
\text { Byrne, 2004 }\end{array}$ & 9 & 28.0 & 31.4 weeks & 10.7 & & 41.8 weeks & 7.2 & & 21.2 & & \\
\hline \multirow{2}{*}{$\begin{array}{l}\text { Blaine, } \\
\text { Rodman, \& } \\
\text { Newman, } \\
2007\end{array}$} & 89 & 44.5 & & 6.0 & -.35 & & & -.55 & & & -.32 \\
\hline & $\begin{array}{l}\text { \# of } \\
\text { studies } \\
\text { included }\end{array}$ & $\begin{array}{l}\text { Average } \\
\text { sample size }\end{array}$ & $\begin{array}{l}\text { Average } \\
\text { weight loss } \\
\text { as } 12 \\
\text { months } \\
(\mathrm{kg})\end{array}$ & $\begin{array}{l}\text { Average } \\
\text { weight loss } \\
\text { at } 36 \\
\text { months } \\
(\mathrm{kg})\end{array}$ & $\begin{array}{l}\text { Short-term } \\
\text { effect of weight } \\
\text { loss treatment } \\
\text { on weight loss } \\
\text { (weighted } r \text { ) }\end{array}$ & $\begin{array}{l}\text { Average } \\
\text { weight loss } \\
\text { at } \\
\text { unspecified } \\
\text { follow-up } \\
(\mathrm{kg})\end{array}$ & & $\begin{array}{l}\text { Long-term effect } \\
\text { of weight loss } \\
\text { treatment on } \\
\text { weight } \\
\text { (weighted } r \text { ) }\end{array}$ & Attrition & $\begin{array}{l}\text { Average } \\
\text { change in } \\
\text { fasting } \\
\text { glucose } \\
(\mathrm{mmol} / \mathrm{L})\end{array}$ & $\begin{array}{l}\text { Long-term } \\
\text { effect of } \\
\text { weight loss } \\
\text { treatment on } \\
\text { depression } \\
\text { (weighted } r \text { ) }\end{array}$ \\
\hline \multicolumn{12}{|l|}{$\begin{array}{l}\text { Surgical } \\
\text { Treatment }\end{array}$} \\
\hline $\begin{array}{l}\text { Maggard et } \\
\text { al., } 2005\end{array}$ & 147 & 120.8 & 51.93 & 53.10 & & & & & 12.0 & & \\
\hline $\begin{array}{l}\text { Buchwald et } \\
\text { al., } 2004\end{array}$ & 136 & 162.5 & & & & 39.7 & & & & -.86 & \\
\hline $\begin{array}{l}\text { Blaine, } \\
\text { Rodman, \& } \\
\text { Newman, } \\
2007\end{array}$ & 28 & 66.1 & 22.9 & & -.29 & & & -.10 & & & -.46 \\
\hline
\end{tabular}

Table 1: Comparison of Weight Loss Outcomes among Behavioral and Surgical Treatment 
APPENDIX B: Bariatric Patient Survey 


\section{Welcome and informed Consent}

The following is a survey of your experience with behavioral and psychological services before and after weight loss surgery. You are eligible to complete this survey only if you had surgery between January 1, 2006 and July 1, 2010 and were at least 18 years of age at the time of your surgery.

The survey is being conducted to fulfill requirements for the completion of a doctoral degree by Jessica Peacock, M.S./M.A. of the Sport and Exercise Psychology department at West Virginia University, under the supervision of associate professor Sam Zizzi, Ed.D. Your participation in this project is greatly appreciated and it will take approximately 15-20 minutes to fill out the survey.

Your involvement in this project will be kept as confidential as legally possible. All data will be reported in the aggregate. You must be 18 years of age or older to participate. You will not be asked any information that should lead back to your identity as a participant. Your participation is completely voluntary. You may skip any question that you do not wish to answer and you may discontinue at any time. West Virginia University's Institutional Review Board acknowledgement of this project is on file.

Should you have any questions about this research, you can contact Jessica Peacock at 304-293-6651 or by email at jessica.peacock@mail.wvu.edu.

We hope that you will participate in this research project, as it could be beneficial for improving the weight loss surgery experience for others. Thank you very much for your time.

By clicking the "Next" button, you acknowledge that you understand the information presented above and willingly agree to participate in this study. 


\section{Pre-Surgical Information}

The following page will ask you questions about your life and habits BEFORE you had surgery. Please take a moment and think back to the time before you had surgery, and then answer the questions below.

1. Moderate physical activities such as brisk walking, bicycling, vacuuming, or gardening, cause small increases in breathing or heart rate.

BEFORE you had surgery, in a usual week, how many days did you do $\mathbf{3 0}$ or more minutes of moderate activity (only count bouts of at least 10 minutes)?

Days of moderate physical activity
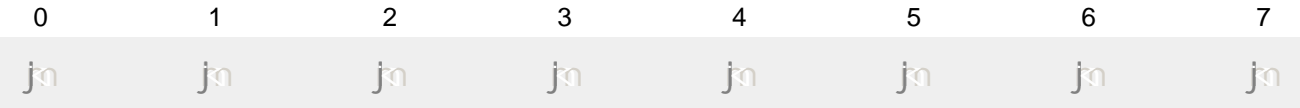

On days when you did moderate activities for at least 10 minutes at a time, how much total time per day did you spend doing these activities? Minutes per day:

2. Vigorous physical activities, such as running, aerobics, or heavy yard work, cause large increases in breathing or heart rate.

BEFORE you had surgery, in a usual week, how many days did you do 20 or more minutes of vigorous activity (only count bouts of at least 10 minutes)?

Days of vigorous physical

activity
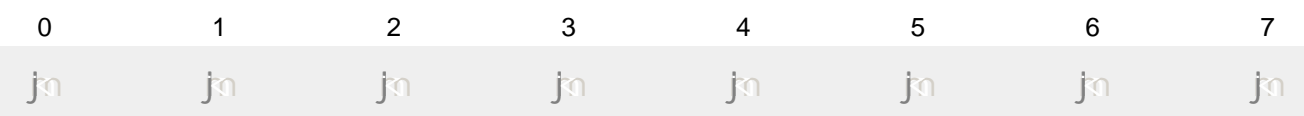

On days when you did vigorous activities for at least 10 minutes at a time, how much total time per day did you spend doing these activities? Minutes per day: 
3. BEFORE having surgery, which of the following had you tried in order to lose weight?

Check all that apply.

Behavior modification

Medication

Meal replacement/liquid diet

Exercise

Jenny Craig

Weight Watchers

Eating plan specific for surgery

Low fat diet

Low carbohydrate/high protein diet

Atkins

Metabolife

Overeaters Anonymous

Any combination of the above

4. For the following question, please indicate whether you were being treated for any of the listed conditions prior to having surgery.

Check as many as are applicable to you.

BEFORE my surgery, I was being treated for:

$\square$ High blood pressure

Asthma

Sleep apnea

Heart disease

Type-2 diabetes

Depression/anxiety

Binge eating disorder

Alcohol or other substance abuse

Other disability 
5. For the following question, please indicate whether you completed the listed services before you had surgery.

\section{Check all that apply to you.}

\section{BEFORE my surgery, I completed the following:}

Informational seminar

Consultation with surgeon or other medical professional

Consultation with a mental health professional

Consultation with a dietician

Consultation with an exercise professional

$\square$ Completion of a one-time educational class

Attendance at a support group(s)

Completion of a program or multiple classes related to lifestyle change 


\section{General Surgical Information}

The following set of questions are related to the general services you received at the surgical facility and your overall surgical experience. There are no right or wrong answers, and we appreciate your honest responses to help our research.

6. Date surgery was completed:

Enter date

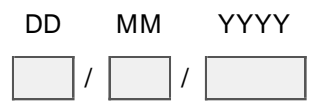

7. Who referred you to your bariatric facility or surgeon?

$\bigcirc$ Primary Care Physician

$\bigcirc$ Urgent Care Center

Mental Health Professional

$\bigcirc$ Dietician

Family member/Friend

$\bigcirc$ Self

Other (please specify)

8. What was your primary motivation for having surgery? Choose the answer that best describes your situation.

$\bigcirc$ Personal choice

Physician recommendation

Please briefly describe why you decided to have surgery:

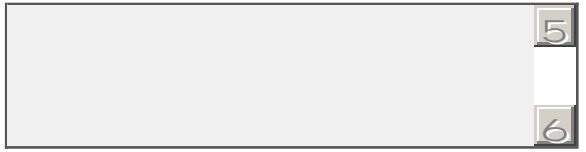

9. In what country was your surgery performed?

$\bigcirc$ United States

Other (please specify) 
10. What weight loss surgical procedure did you undergo?

Roux-en-Y Gastric Bypass

$\bigcirc$ Gastric Band

$\bigcirc$ Sleeve Gastrectomy

Biliopancreatic Diversion

$\bigcirc$ Other (please specify)

11. What is your height?

feet

inches

12. What was your weight (in pounds) at the time of surgery?

13. What was your age (in years) at the time of surgery?

14. What is your current weight (in pounds)?

15. What is your current age (in years)?

16. What was your initial weight loss (in lbs) within the first three months following surgery?

17. At the time of your initial weight loss (within the first three months after surgery), how satisified were you with your surgical experience?

Not at all satisfied

Satisfaction with surgery

after first 3 months
Somewhat satisfied

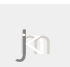

$\bigcirc$
Very satisfied

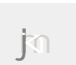

18. Currently, how satisfied are you with your surgery?

Not at all satisfied

Current satisfaction with

surgery
Somewhat satisfied

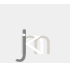

$\bigcirc$

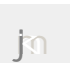

Very satisfied 
19. In the $\mathbf{1 2}$ months after your surgery, how many times did you return for follow-up with the professionals listed below?

(If you had surgery less than $\mathbf{1 2}$ months ago, please indicate how many times you have met with each professional since your surgery)

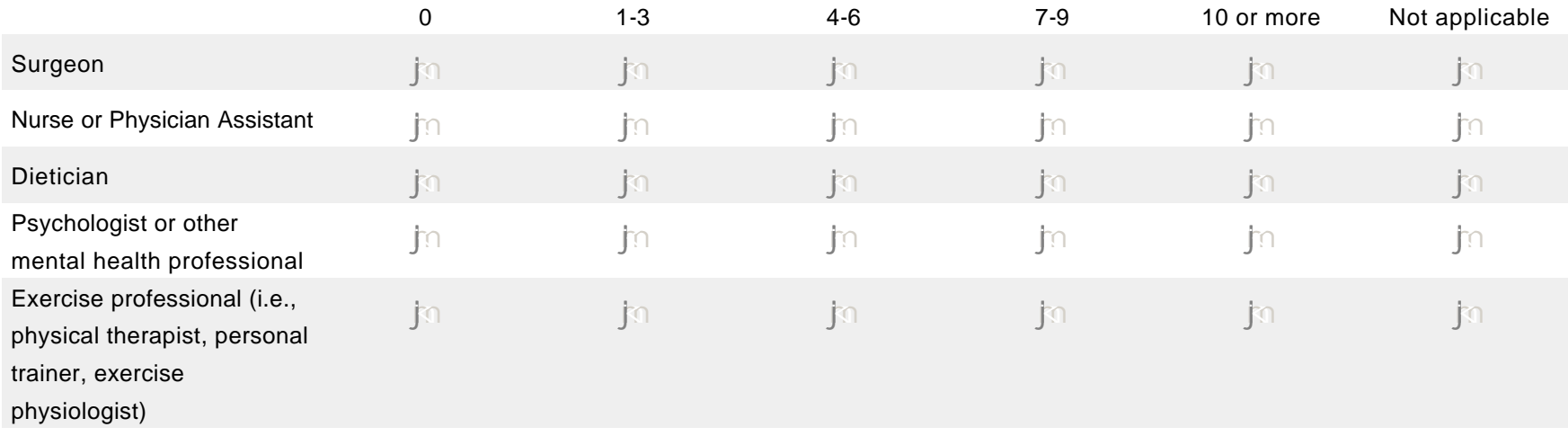

20. Since having surgery, have you experienced any significant medical complication

(s)?

$\bigcirc$ Yes

$\bigcirc$ No

$\bigcirc$ Unsure/Unknown

If yes, please specify what complications you experienced:

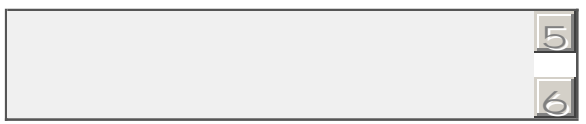




\section{Psychological Services}

The following set of questions pertain to services related to helping you manage your emotions and mental health both before and after surgery.

21. For the following question, please indicate whether you completed the listed services.

Check all that apply to you.

AFTER my surgery, I completed the following psychological services:

Post-surgical individual psychological counseling

Post-surgical group counseling/support group

22. What was the title of the professional you met with for individual psychological counseling (either before or after surgery)?

I did not complete individual psychological counseling

Psychologist

Social worker

Licensed Professional Counselor

$\bigcirc$ Psychiatrist

Unsure/don't know

Other (please specify) 
23. If you attended surgical support groups, what was the title of the professional who led the group? (Check all that apply)

I did not attend any surgical support groups

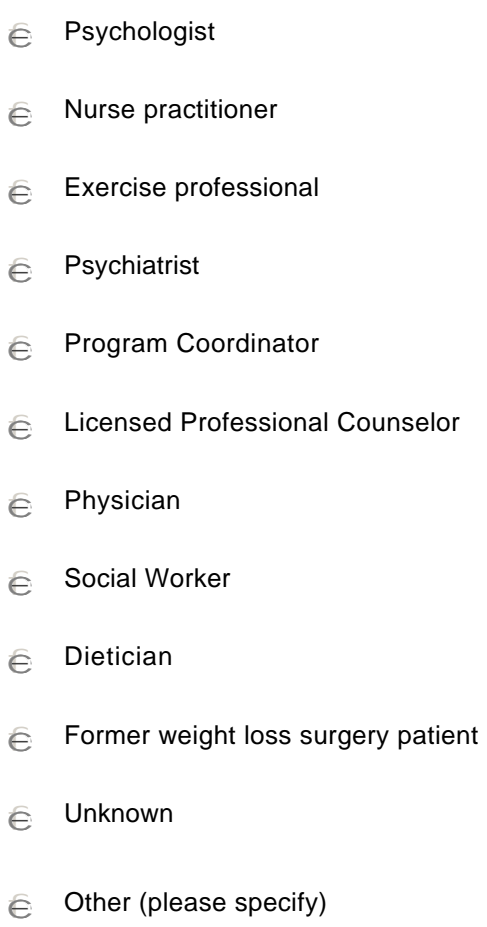

24. Overall, how satisfied are you with the psychological services offered to you by your bariatric facility?

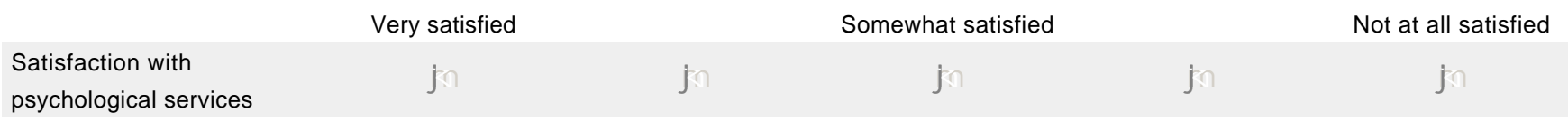

\section{Overall, how satisfied are you with your support group experience?}

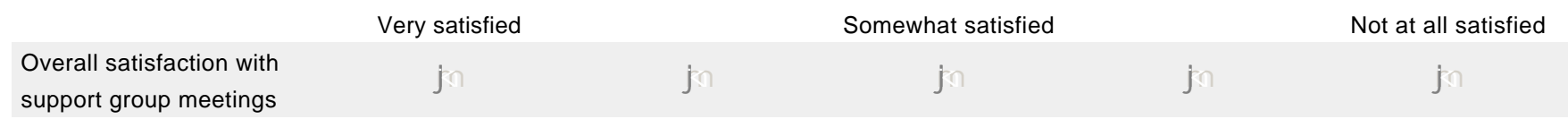

\section{Questions 26-28 will ask you to rate the impact of having surgery on your mental} health and physical health.

3 months BEFORE surgery, I would have described my mental and physical health as being:

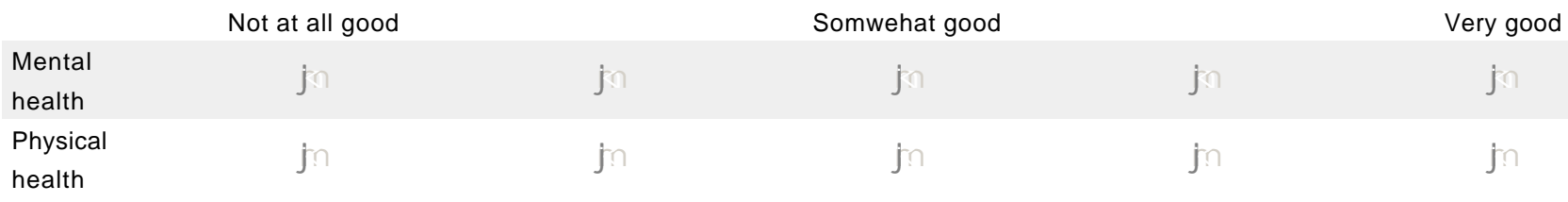


27. 3 months AFTER surgery, the impact of having surgery on my mental and physical health was:

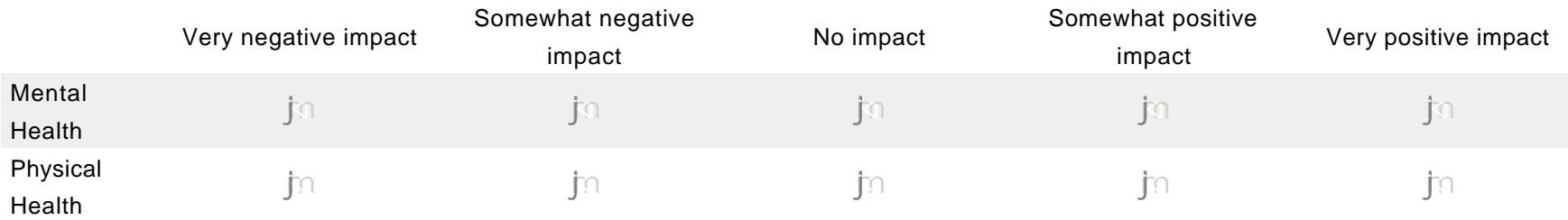

28. CURRENTLY, the impact of having surgery on my mental and physical health is:

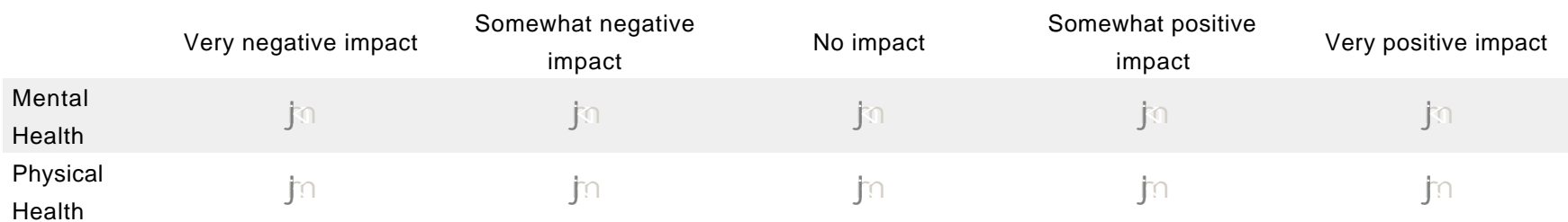

29. Please rate the level of support you received from friends and family for the first 3 months AFTER you had surgery.

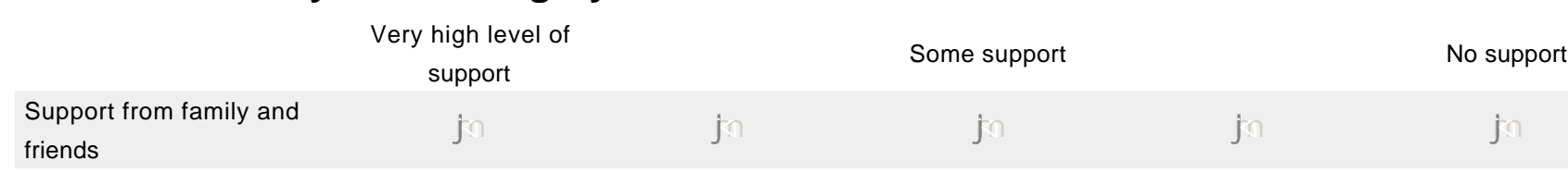

30. What has been the most difficult thing for you to manage psychologically following weight loss surgery?

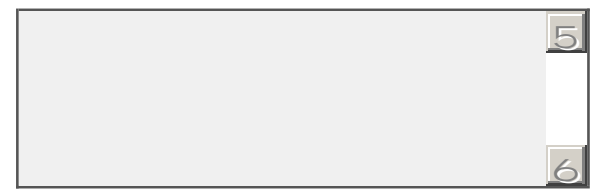

31. What psychological services were most beneficial or helpful to you following weight loss surgery?

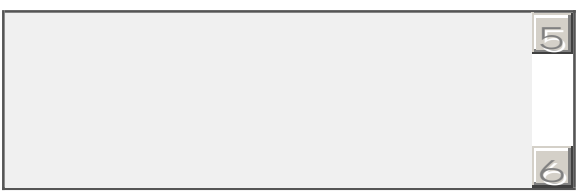

32. If regular psychological counseling had been available to you at your bariatric facility throughout the surgical experience, would you have used this service?

Yes, but only if included in services.

$\bigcirc$ Yes, and I would be willing to pay additional out-of-pocket cost.

This service was available to me during my surgical experience and I did use the service.

No, I would not use this service.

This service was available at my facility and I did NOT use the service. 


\section{Dietary Services}

The following set of questions pertain to services related to helping you make changes to your diet before and after surgery. There are no right or wrong answers, and we appreciate your honest responses to help our research.

33. For the following question, please indicate whether you completed the listed services.

Check all that apply to you.

AFTER my surgery, I completed the following dietary services:

Post-surgical consultation with a dietician

Dietary counseling (meaning three or more sessions with a dietician)

Group classes run by a dietician

34. Questions 34-36 will ask you to rate the impact of having surgery on your eating habits.

3 months BEFORE surgery, I would describe my eating habits as:

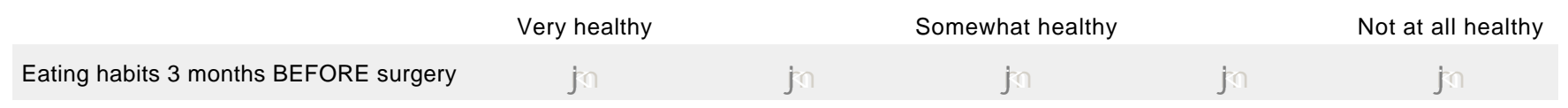

35. 3 months AFTER surgery, the impact of having surgery on my eating habits was:

pact of surgery on eating habits 3

months AFTER surgery

Very positive Somewhat positive impact

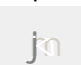

impact

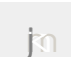

No impact

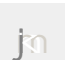

Somewhat negative impact

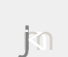

Very negative impact

36. CURRENTLY, the impact of having surgery on my eating habits is:

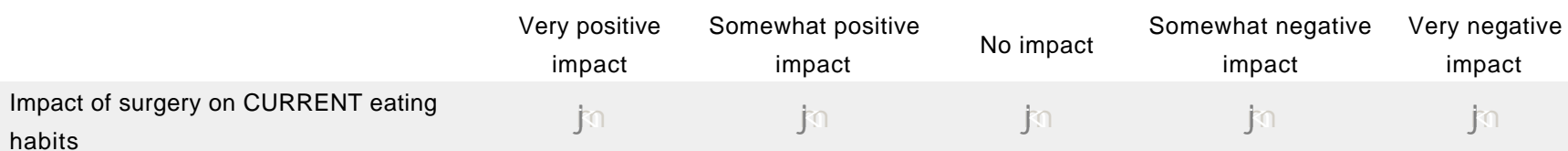

37. How would you describe changes you have made to your eating habits since weight loss surgery?

I have not changed my eating habits

My eating habits have changed somewhat

My eating habits have changed significantly 
38. Before or after your surgery, were you exposed to information or education on any of the following?

Identifying and planning for barriers to

healthy eating

Finding support for healthy eating

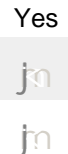

$\bigcirc$
No
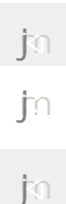

Unsure/Don't know

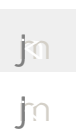

$\bigcirc$

If you responded "yes" to any of the above, who provided you information on these topic(s)?

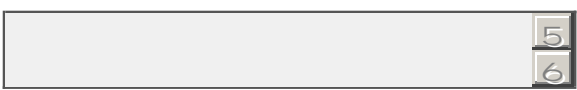

39. Overall, how satisfied are you with the dietary services offered to you at your bariatric facility?

Satisfaction with dietary
services

Not at all satisfied
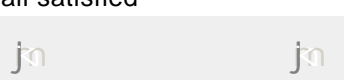

Somewhat satisfied

services

40. What has been the most difficult thing for you to manage related to your diet following weight loss surgery?

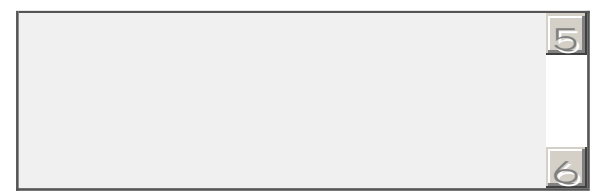

41. What dietary services were most beneficial or helpful to you following weight loss surgery?

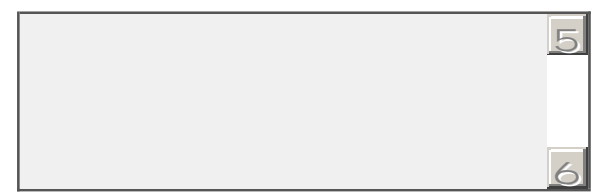




\section{Exercise Services}

The following set of questions pertain to services related to helping you increase physical activity before and after surgery. There are no right or wrong answers, and we appreciate your honest responses to help our research.

42. For the following question, please indicate whether you completed the listed services.

Check all that apply to you.

AFTER my surgery, I completed the following exercise-related services:

Post-surgical consultation with an exercise professional

Exercise counseling (meaning 3 or more sessions with an exercise professional)

Group sessions run by an exercise professional

43. Before or after your surgery, were you exposed to information or education on any of the following:

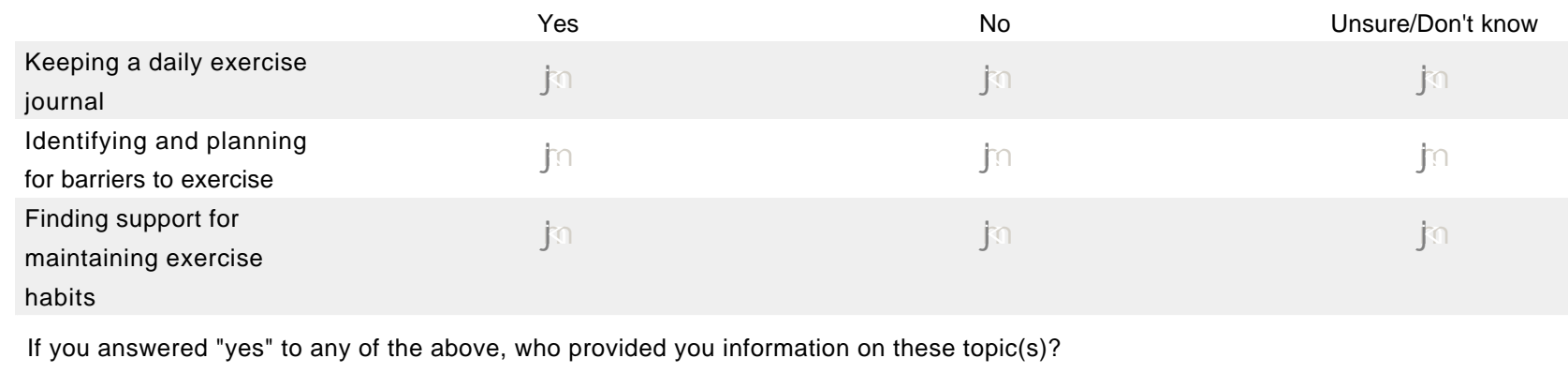

44. This question asks you to rate the impact of having surgery on your physical activity habits 3 months AFTER surgery.

Physical activity is defined as "movement of the body that uses energy" and can include walking, climbing stairs, housework, and other activities you do daily.

3 months AFTER surgery, I would describe my physical activity levels as being:

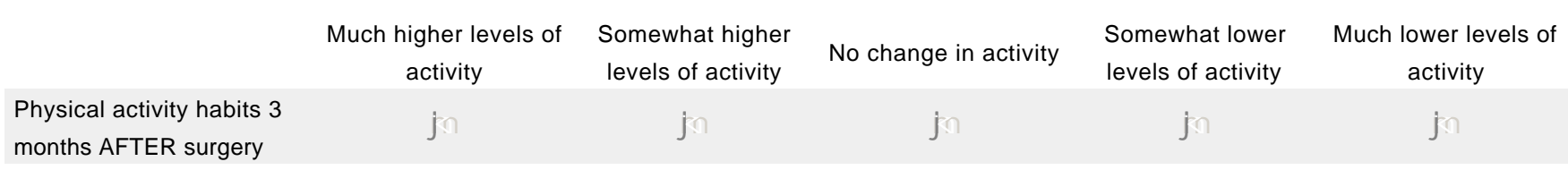


45. How would you describe changes you have made to your exercise habits since weight loss surgery?

I have not changed my exercise habits

My exercise habits have changed somewhat

My exercise habits have changed significantly

46. What has been the most difficult thing for you to manage related to exercise following weight loss surgery?

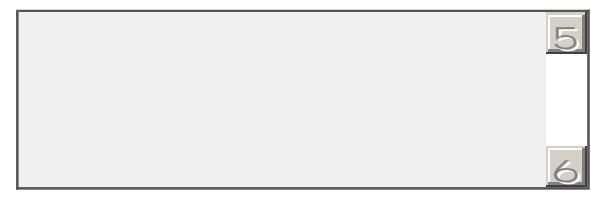

47. What was the title of the individual you met with for exercise counseling or consultation (either before or after surgery)?

I did not complete exercise counseling or consultation

$\bigcirc$ Physical therapist

$\bigcirc$ Exercise physiologist

$\bigcirc$ Personal trainer

$\bigcirc$ Exercise specialist

Unknown

Other (please specify) 
7. Exercise Services 2

48. How satisfied are you with the exercise services offered to you at your bariatric facility?

Not at all satisfied
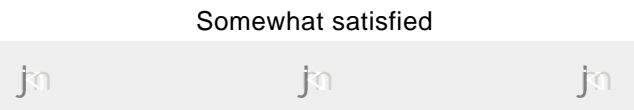

Very satisfied

Satisfaction with exercise

services

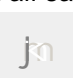

49. What exercise services were most beneficial or helpful to you following weight loss surgery?

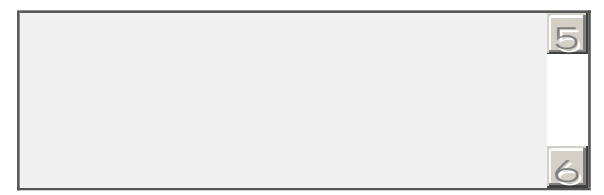




\section{Lifestyle Services}

The following set of questions pertain to services provided to help you make overall lifestyle change before and after surgery. "Lifestyle change" is considered permanent change to your overall way of living and includes increased healthy eating habits and exercise.

50. For the following question, please indicate whether you completed the listed service.

AFTER my surgery, I completed the following lifestyle services:

Group classes or counseling regarding how to change a behavior/lifestyle

51. During your surgical experience, were you exposed to information or education on any of the following?

Setting effective goals

If you responded "yes" to any of the above, who provided you information on these topic(s)?

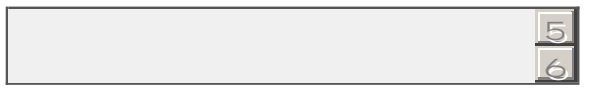

52. If a program had been available to you at your bariatric facility to help you change your lifestlye and behavior, would you have attended?

Yes, but only if included in services.

$\bigcirc$ Yes, and I would be willing to pay additional out-of-pocket cost.

This service was available to me during my surgical experience and I did use the service.

No, I would not use this service.

This service was available at my facility and I did NOT use the service. 


\section{Current Diet and Physical Activity Habits}

You're almost done! This page will ask you to report on your CURRENT eating and exercise habits. Take a moment and think about the foods you eat on a typical day, and how much activity you complete in an average week. Then answer the following:

53. The following question asks about the fruits and vegetables you usually eat.

Examples of a serving of fruit include 1 medium apple, banana, or orange; $1 / 2$ cup of chopped, cooked or canned fruit; and $3 / 4$ cup of $100 \%$ fruit juice.

Examples of a serving of vegetables include 1 cup of raw leafy vegetables; $1 / 2$ cup of other vegetables cooked or chopped raw; and $3 / 4$ cup of $100 \%$ vegetable juice.

On a typical day, how many servings of fruits and vegetables do you eat?

Servings of Fruit per day

Servings of Vegetables per day

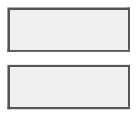

54. Moderate physical activities such as brisk walking, bicycling, vacuuming, or gardening, cause small increases in breathing or heart rate.

In a usual week, how many days do you do $\mathbf{3 0}$ or more minutes of moderate activity (only count bouts of at least 10 minutes)?

Days of moderate physical
activity

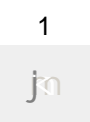

$\bigcirc^{2}$

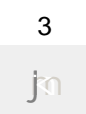

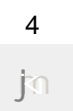
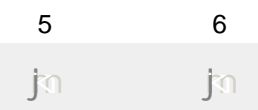

7

On days when you do moderate activities for at least 10 minutes at a time, how much total time per day do you spend doing these activities? Minutes per day: 
55. Vigorous physical activities, such as running, aerobics, or heavy yard work, cause large increases in breathing or heart rate.

In a usual week, how many days do you do $\mathbf{2 0}$ or more minutes of vigorous activity (only count bouts of at least 10 minutes)?

Days of vigorous physical

activity
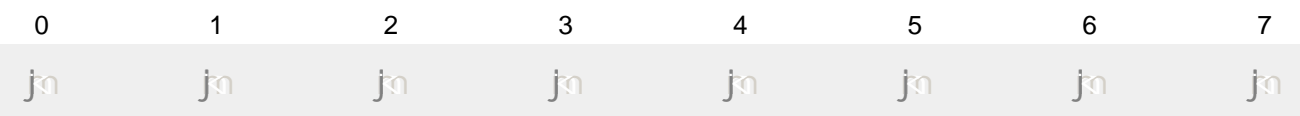

On days when you do vigorous activities for at least 10 minutes at a time, how much total time per day do you spend doing these activities? Minutes per day:

56. Do you complete strength training (i.e., lifting weights, using resistance bands, other weight-bearing activities) on a regular basis?

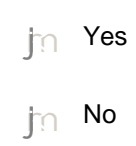

If yes, please specify how many days per week you complete strength training. 


\section{Demographic Information}

The following set of questions ask for demographical information such as your gender and marital status. This information cannot be used to identify you in any way, and your responses will remain anonymous and confidential.

57. What is your gender?

$\bigcirc$ Male

Female

$\bigcirc$ Other (please specify)

58. Which of the following best describes your race/ethnicity?

White

Black or African American

Hispanic

Asian

Native Hawaiian or Other Pacific Islander

American Indian or Alaska Native

Other (please specify)

59. What is your marital status?

Single

$\bigcirc$ Married

$\bigcirc$ Divorced

$\bigcirc$ Separated

$\bigcirc$ Widowed

$\bigcirc$ Other (please specify)

60. Do you have children living at home?

$\bigcirc$ Yes

No 
61. What is your household's current annual income?

\0-19,999

\20,000-39,999

$\bigcirc \$ 40,000-59,999$

$\bigcirc \$ 60,000-79,999$

$\bigcirc \$ 80,000-99,999$

$\bigcirc \$ 100,000$ or greater

Decline to answer

\section{What is your highest educational level?}

Some high school

High school diploma

$\bigcirc$ some college

$\bigcirc$ College degree

Some graduate work

$\bigcirc$ Graduate or professional degree

$\bigcirc$ Other (please specify)

\section{When you are at work, which of the following best describes what you do?}

Mostly sitting or standing

$\bigcirc$ Mostly walking

Mostly heavy labor or physically demanding work

$\bigcirc$ Retired

$\bigcirc$ Not currently employed 
64. For the following question, please indicate whether you are currently being treated for any of the listed conditions.

Check as many as are applicable to you.

CURRENTLY, I am being treated for:

High blood pressure

Asthma

Sleep apnea

Heart disease

Type-2 diabetes

Depression/anxiety

Binge eating disorder

Other disability

\section{What insurance company covered the cost of your surgery?}

I paid my own surgical costs

UnitedHealth Group

$\bigcirc$ WellPoint

$\bigcirc$ Aetna

$\bigcirc$ Humana

$\bigcirc$ Cigna

$\bigcirc$ Health Net

$\bigcirc$ Coventry Health Care

$\bigcirc$ Amerigroup

$\bigcirc$ Universal American

$\bigcirc$ Centene

$\bigcirc$ Blue Cross/Blue Shield

Kaiser Permanente

$\bigcirc$ Medicare/Medicaid

$\bigcirc$ Other (please specify) 


\section{Thank You}

Thank you for your participation in this study. If you have any questions about this research, you can contact Jessica Peacock at 304-293-6651 and jessica.peacock@mail.wvu.edu, or Dr. Sam Zizzi at 304-293-0874. For information regarding your rights as a research subject, you may contact the Office of Research Compliance at 304-293-7073.

If you reported experiencing medical or psychological complications related to your surgery that are not currently being treated, we recommend that you seek assistance from your surgeon or primary care physician immediately. 